\author{
RENATO GONZÁLEZ MELLO \\ INSTITUTO DE INVESTIGACIONES ESTÉTICAS, UNAM
}

\title{
La UNAM y la Escuela Central de Artes Plásticas durante la dirección de Diego Rivera
}

\section{Planteamiento}

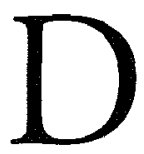

iggo Rrvara fue director de la Escuela Central de Artes Plásticas, continuación de la vieja Academia, ${ }^{\mathrm{I}}$ entre agosto de 1929 y mayo de 1930. ${ }^{2}$ Salió de ahí por un movimiento estudiantil organizado en su contra. En agosto de 1929, pocos meses después de conseguida la autonomía de la Universidad Nacional de México, su máximo cuerpo colegiado, el Consejo Universitario, se encontró con que había demasiados representantes de la Escuela Nacional de Bellas Artes porque en ella coexistían, desde su fundación, profesores, estudiantes y autoridades de dos instituciones: la Facultad de Arquitectura y la ENBA propiamente dicha. El Consejo Universitario (en adelante $\mathrm{cu}$ ) resolvió dividirlas; con extraña rapidez, que hace pensar en una acción premeditada, se propuso a Diego Rivera como director de la nueva

1. En este texto usaré los nombres de Academia o fCap (Escuela Central de Artes Plásticas) para referirme a la misma institución. En otros periodos, algunos de los cuales son mencionados en este texto, se llamó Escuela Nacional de Bellas Artes (ENBA) y así me refiero a ella cuando se trata de ese tiempo.

2. Se han ocupado del asunto Raquel Tibol, comp., Diego Rivera: arte y politica, México, Grijalbo, 1979 ('Teoría y Praxis); Francisco Reyes Palma, Historia social de la educación artística en México, México, Instituto Nacional de Bellas Artes, 1984; Laura González Matute, $13^{0-}$ 
Escuela Central de Artes Plásticas (en adelante ECAP) y se aprobó su candidatura. ${ }^{3} \mathrm{Si}$ acaso había una facción inconforme con la solución del problema, ésta fue tomada por sorpresa y no tuvo tiempo de organizarse, como notoriamente ocurrió después.

En marzo de 1930 se discutió un plan de estudios para la ECAP propuesto por el nuevo director en una comisión permanente, parecida a la del Congreso de la Unión, que tenía el cu. ${ }^{4} \mathrm{El}$ plan de Rivera se aprobó, pero con la oposición de algunos representantes de la Facultad de Arquitectura. El debate sobre el plan de estudios continuó y se extendió. A fines de abril, los estudiantes de arquitectura se inscribieron masivamente en materias sueltas de artes plásticas, se apoderaron de la sociedad de alumnos de la ECAP y nombraron representantes ante las Academias Mixtas de Profesores y Alumnos 5

30! contra la Academia de Pintura, catálogo de exposición en el Museo Nacional de Arte, incluye estudio, documentos y folletería, México, Instituto Nacional de Bellas Artes, Museo Nacional de Arte, 1993, y Karen Cordero Reiman, "Alfredo Ramos Martínez: 'un pintor de mujeres y de flores' ante el ámbito estético postevolucionario", en Alfredo Ramos Martínez (I871-1946), una visión retrospectiva, catálogo de exposición en el Museo Nacional de Arte, abril-junio de 1992, México, Instituto Nacional de Bellas Artes, Museo Nacional de Arte, 1992, pp. $6 \mathrm{r}-78$.

3. Centro de Estudios sobre la Universidad (en adelante cEsu), fondo Consejo Univetsitario (en adelante CON-UNI), caja 20 , exp. I44, ff. 8-I5; exp. I46, ff. 5-40, y exp I47, ff. $5 \mathrm{I}-57$ También El Nacional Revolucionario, México, I6 agosto 1929, P. II-I.

4. Pese a haber numerosas referencias a esta discusión, que ya iremos viendo, no pude encontrarla en las actas del Consejo Universitario que se guardan en el cesu, ni en las que conserva la secretaría del propio CU. Por ejemplo, sé refiere a ella el secretario de la UNAM, el abogado José López Lira, en el "Acta y transcripción taquigráfica de la sesión del Consejo Universitario del I4 de mayo de 1930", en Archivo del Consejo Universitario, Secretaría Ejecutiva, actas, sesiones, resúmenes, 2 enc., A-7, I4 de mayo de 1930 (en adelante "Acta y transcripción taquigráfica..."), p. 265 . Quizá por ser una sesión de comisión permanente no se tenía el mismo cuidado paka registrar los hechos que en las sesiones plenarias. Un ejemplar impreso del plan de estudios publicado en 1928 , al que me referiré más adelante, que se conservó en la sección de la ENBA del CESU, tiene tachada con lápiz la fecha de 1928 y escrito "I929". En este ejemplar, la parte de "Estudios especiales de pintura y escultura" está tachada con lápiz rojo, y dice al margen (p. 4) "Véase el nuevo plan": "Ejemplar impreso del plan de Estudios de la Escuela Nacional de Bellas Artes", CEsu, fondo Escuela Nacional de Bellas Artes (en adelante ESC-NAI), caja I, exp. 3, s.n., I929. Llegué a este documento porque la licenciada Flora Elena Sánchez Arreola me permitió ver su índice inédito de la sección de la ENBA del CESU, por lo que le estoy muy agradecido. En adelante, todos los documentos que encontré en su índice quedarán indicados con las siglas "FESA".

5. Órgano colegiado interno que renía cada escuela universitaria. 
ante el cu. En la tarde del día 23, una reunión de profesores eligió representantes ante las mismas instancias y expresó su apoyo a Rivera frente a la inquietud estudiantil, pero después, a sus espaldas, los mismos profesores "resolvieron" que Rivera pidiera una licencia y que se nombrara director interino a Carlos Dublán. No sólo eso: de inmediato se convocó a la Academia Mixta sin pedir el consentimiento de Rivera.

El 29 de abril, el cu integró una comisión para estudiar el conflicto, integrada por Luis Chico Goerne, Alejandro Gómez Arias, José Enrique Zapata y Horacio Núńez. ${ }^{6}$ Ésta recomendó, en la sesión del i4 de mayo, que un director interino asumiera la conducción de la ECAP en tanto se determinaba quiénes sí eran estudiantes de la misma y para ver si Rivera contaba con el apoyo de los alumnos. ${ }^{7}$ Entonces ardió Troya. Antonio Caso amenazó con renunciar a la dirección de la Facultad de Filosofía y Letras si se aprobaba esa propuesta, pues ello restaría autoridad a la figura del director. Después de una prolongada y ríspida sesión, Riveta renunció a su puesto. ${ }^{8}$

Este artículo es una interpretación de esos hechos bien conocidos. Trataré de revisar dos cosas. Primero, qué era lo que estaba en disputa: cuáles eran los planes de estudio que se proponían y desde qué puntos de vista. Compararé el plan de estudios de Rivera con el que estaba vigente cuando se hizo cargo de la ECAP. Esa comparación será crítica: al analizar la estructura y exigencias del plan de Rivera quedará en duda la posibilidad de cumplir sus fines declarados de beneficiar a la clase obrera.

Después revisaré el debate propiamente dicho: tanto los argumentos como la forma y las circunstancias en que se dijeron. El objetivo de este ejercicio será entender qué clase de conflicto fue el que acabo de reseñar: si un conflicto "generacional", un conflicto "ideológico", un conflicto "de clase"; o bien discutir la validez de esas categorías de análisis. En esta segunda parte se

6. Luis Chico Goerne, et al., "Dictamen que somete a la consideración del H. Consejo Universitario la comisión", I4 de mayo de 1930 (en adelante Chico Goeme et al., "Dictamen que somete..."), CESU, fondo Rectoría (en adelante REC), caja 3I, exp. 298 (antes caja I, exp. 2.), pp. $71-75$

7. En esos lejanos y felices tiempos se pensaba que "la dirección de cualquiera Facultad o Escuela [.... debe estar en todo momento apoyada en la gran mayoría de alumnos y profesores"; ibidem.

8. "Acta y transcripción taquigráfica ...", 273 p. Al documento anterior le faltan elementos importantes, por lo que es necesario compararlo con la crónica periodística "Renunció a la dirección de la Escuela de Artes Plásticas, el pintor Diego Rivera, anoche", en El Nacional RevoLucionario, I5 de mayo de 1930 (en adelante "Renunció a la dirección de la Escuela ...."), p. 7. 
verá que la actuación y el fracaso de Rivera como director están estrechamente ligados a la Universidad en el momento de iniciarse su vida autónoma. Este texto trata de llamar la atención sobre la imbricación, a veces marginal pero constante, de la universidad en la historia cultural mexicana de este siglo.

Lo que se relata en seguida sin duda fue un precedente para que la Academia perdiera el papel central que había tenido hasta entonces en la pintura mexicana, tema que escapa al alcance de estas líneas. Más allá de eso, no cteo que esta pequeña crisis, esta tormenta en un vaso de agua, fuera determinante para algo en especial. Aunque quizá los acontecimientos aparezcan dramatizados en la narración, mi interés no es hablar del momento decisivo, sino hacer la "crónica de un instante", con la hipótesis de que ese procedimiento permitirá entender mejor lo que ocurrió en un lapso muchísimo mayor; tanto, que en ocasiones los personajes actúan, sin saberlo del todo, en una historia que había comenzado antes de su nacimiento. Otras veces el lector se sorptendetá con la sensación de que lo narrado todavía no termina, de que los hechos representados aquí son, en cierta forma, sus propios hechos (sobre todo si es universitario).

\section{Los planes de estudio}

En el debate al que me he referido estaban en juego distintas posiciones sobre el plan de estudios. La Academia había tenido incidentes parecidos desde la llegada de Antonio Fabrés. ${ }^{9}$ Su situación de crisis parecía ininterrumpida desde principios de este siglo; una inestabilidad, por cierto, fecunda. De ella surgieron los más impottantes pintores mexicanos de su tiempo: no sólo Rivera, Orozco y Siqueiros; también Tamayo, Montenegto, Herrán y muchos otros habían estudiado en esta escuela en transformación perpetua.

9. Véanse Fausto Ramírez, "Tradición y modernidad en la Escuela Nacional de Bellas Artes, 1903-1912", en Las academias de arte VII Coloquio Internacional de Historia del Arte, México, Universidad Nacional Autónoma de México, Instituto de Investigaciones Estéticas, 1985, p. 209; Jean Charlot, Mexican Art and the Academy of San Carlos, 1785-1915, Austin, Texas University Press, I962, y Raquel Tibol, "Las escuelas al aire libre en el desarrollo cultural de México", en Sylvia Pandolfi, comp., Homenaje al movimiento de escuelas de pintura al aire libre, México, Instituto Nacional de Bellas Artes, 198r, pp. 16-49. 
Fue Alfredo Ramos Martínez quien instituyó la práctica académica que Rivera quiso modificat. Como se recordatá, Ramos Martínez había instaurado una "Escuela de Pintura al Aire Libre", de tendencia impresionista, en 1913. Vasconcelos lo nombró nuevamente director en r92.0 y Ramos Martínez volvió a sus institutos campiranos, pero esta vez con otras ideas: ${ }^{10}$ ya no solamente para enseñar a estudiantes de pintura, sino también y, de preferencia, a niños indígenas de las localidades donde se instalaban escuelas al aire libre. A la par de este proceso, siguió habiendo en la Academia estudiantes que buscaban profesionalizarse. En un plan de estudios que elaboró en 1927 se menciona la existencia de "estudios especiales de pintura" y de escultura, con alumnos regulares que se inscribirían en "talleres libres" que podrían estar en las escuelas de pintura al aire libre o en el edificio principal de la Academia. Para obtener su título de pintor, cada estudiante debía inscribirse en alguno de esos talleres anualmente, por un periodo de cinco años. El "plan de estudios" era bastante permisivo, pues se especificaba que "el profesor de cada taller estará en absoluta libertad de seguir su método personal de enseñanza y será, así mismo, el único responsable de los resultados que obtengan sus alumnos". "El plan otorgaba tanta libertad que casi negaba la esencia normativa de cualquier plan de estudios. Ramos Martínez, según los testimonios de que disponemos, también procuraba dar la mayor libertad posible a los estudiantes dentro de su propio taller. ${ }^{\text {I2 }}$

El plan de Ramos Martínez buscaba conciliar las vanguardistas escuelas de las chinampas con la permanencia de numerosos profesores académicos que, sin embargo, no eran parte de ese proyecto expresionista: Romano Guillemín, Carlos Lazo, ${ }^{\text {I3 }}$ Mateo Herrera, Alberto Garduño, Alfonso Garduño, Emilio García Cahero, Eduardo Solares, Germán Gedovius je incluso el viejo Leandro Izaguirre! ${ }^{I 4}$ Que siguieran siendo profesores académicos no quiere

Io. Cordeto Reiman, op cit., pp 6I-78, se refiere a esta segunda etapa en el magistetio del pintor:

II. "Doce ejemplares del plan de Estudios de la Escuela Nacional de Bellas Artes", CEsU, ESC-NAI (FESA), caja 20 (antes 2I), exp. I, 21 de enero de 1928, p. 4

12. Véase el testimonio de Fernando Leal en Charlot, op. cit., p. I6I. De paso, es interesante señalar que esa cita no corresponde con las "reminiscencias" de Leal en Jean Charlot, El renacimiento del muralismo mexicano, 1920-1925, México, Domés, 1985, pp. 195-207, por lo que valdría la pena buscat en los archivos de Charlot el original de las "reminiscencias"; es posible que falte todavía más.

13. Que era el encargado de las clases de historia del arte

14. En 1926 se les menciona a todos como profesores de "cursos libres", en "Materias que 
decir que fueran una colección de momias. Algunos incluso habían sido discípulos o partidarios de Ramos Martínez, cuyo plan de estudios les daba autonomía absoluta en la enseñanza. Esta última adquiría un carácter artesanal; no había "estudiantes" sino aprendices en el taller de un maestro. Dicha situación no era enteramente nueva: aunque durante el siglo xIx y los primeros años del xx se ensayaron distintos planes de estudio, algunos muy minuciosos, los testimonios más importantes sobre el aprendizaje de la pintura nos hablan de relaciones personales en las que un estudiante seguía de preferencia a un profesor. Tal fue la formación de Velasco con Landesio ${ }^{\text {rs }}$ o de Rivera con Velasco y Rebull, con quien imaginaba una relación casi familiat. ${ }^{16}$ El plan de Ramos Martínez extremaba una tendencia de las que se habían disputado la Academia desde tiempo atrás: la que, con inspiración romántica, intentaba reconstruir la enseñanza medieval. Por eso daba el mayor peso a la enseñanza en el taller y a la transmisión no libresca, no académica sino personal de los conocimientos.

Conocemos también un proyecto anónimo fechado en abril de 1929, acaso elaborado durante la breve dirección de Manuel Toussaint (diciembre de 1928 a agosto de 1929) para limitar el plan de Ramos Martínez. Dicho documento indica que se planeaba implantar clases de idiomas, de historia y materias aisladas de anatomía, perspectiva y preparación de colores, aunque éstas no iban a ser, como antaño, la columna vertebral de la carrera. El mayor peso de los estudios seguiría teniéndolo el "taller libre de pintura", al que cada alumno tendría que inscribirse todos los años. ${ }^{17}$ Quizá contra este proyecto se desarrollaron las protestas de los jóvenes reunidos en el j30-30!, el cual buscaba desacreditar a la "academia" y defender a las escuelas al aire libre. Entre las demandas de esa agrupación estaba destituir a Toussaint y a una interesante lista de profesores: Sóstenes Ortega, Eduardo Solares, Roma-

desean cursar los inscritos en los cursos libres", CESU, ESC-NAI (FESA), caja 9, exp. 2, 3116, 192.6 y exp $3,94,1926$.

I5. María Elena Altamirano Piolle, "José María Velasco: paisajes de luz, horizontes de modemidad", en Homenaje Nacional a José Maria Velasco (1840-19I2), catálogo de exposición en el Museo Nacional de Arte, julio-octubre de 1993, México, Instituto Nacional de Bellas Artes-Museo Nacional de Arte, Amigos del Museo, 1993, vol. I, pp. roI-II5, se refiere a la formación de Velasco al lado de Landesio.

16. Loló de la Torriente, Memoria y razón de Diego Rivera, México, Renacimiento, 1959, vol I, pp. 2.27 y 238 .

17. "Plan de estudios de la Escuela de Pintura y Escultura", CeSU, eSC-NAI (FesA), caja i7 exp. 7, s.n., abril de 1929 
no Guillemín, Guilberto Chávez [sic], Ignacio Asúnsolo, J.M. Fernández Urbina, Abelardo Carrillo y Gariel, Germán Gedovius, Francisco Concha, Leandro Izaguirre, Luis Albarrán, José Tovar, Carlos Lazo y Armando Drechsler. Nombres más, nombres menos, ellos fueron los mismos que, para defenderse de Fernando Leal y sus amigos, se reunieron en una efímera asociación llamada Ruta; los mismos que después se opondrían con todas sus fuerzas al proyecto de Rivera. ${ }^{18}$ Se trata de un grupo de gente formada en las primeras dos décadas del siglo, en una academia donde el mayor peso de los estudios recaía sobre el dibujo "del natural" y sobre el uso de los materiales de la pintura, según recuerdan Orozco y Siqueiros. ${ }^{19}$ A principios de los años treinta, Orozco tecordaba aproximadamente la misma lista de personas como los alumnos y profesores más significativos de la Academia durante los años en que él pasó por ahí: eran los alumnos de Fabrés, que luego lo habían sido de Gedovius; ${ }^{20}$ los mismos que después estatían involucrados en la huelga contra Rivas Mercado y algunos de los cuales se irían con el Doctor Atl a La Vanguardia; ${ }^{21}$ los mismos que, en fin, habían sido dueños y señores del

I8. González Matute, op cit., folletería. Véanse las listas de opositores a Rivera, coincidentes con la proporcionada, en "Los estudiantes defienden la labor de Diego Rivera", en El Nacional Revolucionario, 4 de mayo de 1930, P. I-I.; "Se sigue ahondando el cisma en la Escuela de Artes Plásticas", en ibidem, io de mayo de 1930, pp. I-I y I-7, y sobre todo "Es fácil la resolución del problema estudiantil", en ibidem, 2.7 de abtil de 1930, pp. I y 6 .

19. José Clemente Orozco, Autobiografia, México, Era-Secretaría de Educación Pública, 1983, pp. II, I3, 2.1 y 24; David Alfaro Siqueiros, Me llamaban "El Coronelazo", México, Grijalbo, 1977 (Biografias Gandesa), pp 83 y 88-89

20. Orozco, op. cit., p. 24; Salvador Moreno, El pintor Antonio Fabrés, México, Universidad Nacional Autónoma de México, Instituto de Investigaciones Estéticas, 198I, p. 216, y Fausto Ramírez, "La obra de Germán Gedovius: una reconsideración", en Germán Gedovius, una generación entre dos siglos, catálogo de exposición en el Museo Nacional de Arte, México, Instituto Nacional de Bellas Artes, I984, pp. I6-17. No es el caso de todos, sin embargo. José de Jesús Ibarra, expulsado en rgrı por sumarse a la protesta contra Rivas Mercado, era a fines de los años veinte miembro del Bloque de Obreros Intelectuales, no muy cercano a los maestros conservadores de la Academia. Véase Pilar García, "Alfredo Ramos Martínez y la Academia Nacional de Bellas Artes", en Alfredo Ramos Martinez (I87x-I946), una visión retrospectiva, catálogo de exposición en el Museo Nacional de Atte, abtil-junio de 1992, México, Instituto Nacional de Bellas Artes, Museo Nacional de Atte, 1992, pp. 42-43.

2I. En una carta incluida en Luis Cardoza y Aragón, Orozco, México, Universidad Nacional Autónoma de México, Instituto de Investigaciones Estéticas, 1959, pp. 298-303, Orozco los menciona en un intento específico de restar importancia a la participación de Rivera en la histotia del arte contemporáneo mexicano. Véanse también, en La Vanguardia Ilustrada, especial de La Vanguardia, Orizaba, 23 de junio de 1915, pp. 6-7, las caricaturas de los partici- 
terreno en la década de los años diez ${ }^{22}$ y que se habían visto desplazados de la escena pública al principio de los veintes con el retorno de Diego Rivera. Seguramente había aversión, y era recíproca: Rivera tenía poca simpatía por ese grupo de profesores y sus métodos. Alumno de Rebull y de Velasco, sus relaciones con Fabrés no fueron buenas. ${ }^{23}$ En los años cuarenta recordaba con bastante desagrado a los que "se sentían ultramodernistas por empezar a ensayar en r9or el impresionismo de I846... [y] despreciaban al viejo Rebull" ${ }^{24}$ ¿Autocrítica? También Rivera había ensayado ese impresionismo anacrónico, pero renegó de él y lo combatió violentamente a partir de su retorno de Europa. ${ }^{25}$

Vistas así las cosas, no sorprende que los profesores de la Academia se hayan peleado con Rivera. Su plan de estudios planteó cambios radicales en tres órdenes, que veremos sucesivamente: transformaba completamente las características de los estudiantes, imponía un lenguaje vanguardista y, sobre todo, propugnaba el regreso a métodos de enseñanza que se habían dejado de usar décadas atrás.

\section{La Academia y la clase obrera}

El botrador de un cartel propagandístico de la Academia riveriana presumía:

La Escuela de Artes Plásticas abre cursos nocturnos a los que llama muy especialmente a los proletarios. El arte entendido en su verdadero valor social y técnico puede capacitarlos para mejorar sus salatios y tecibir mayor compensación en la vida, por la belleza que pueden aprender a crear ${ }^{26}$

pantes en el periódico: Atl, Cabildo, Castillo Ledón, Becerra Acosta, Giffard, Ochoa, Romano Guillemín, Francisco Centeno (director de la Facultad de Arquitectura cuando se desarrollaban los sucesos de I930) y Fernández.

22. Sus nombres apatecen insistentemente en la correspondencia entre Alfonso Reyes y Pedro Henríquez Ureña. Véase José L uis Martínez, comp., Alfonso Reyes-Pedro Henríquez Ureña: correspondencia re07-1914, México, Fondo de Cultura Económica, r986, vol. I, pp. 22.2-223.

23. Moreno, op cit, p 213, da noticia de que Fabrés expulsó a Rivera de sus clases

24. De la Torriente, op cit., vol. I, pp. 22.7 y 233-2.34.

25. Véanse los textos reproducidos en Xavier Moyssén, comp., Diego Rivera, textos de arte, México, Universidad Nacional Autónoma de México, 1986, pp 39-4I y 49-56.

26. "Escuela Central de Artes Plásticas de México", Cesu, RfC, caja 31, exp. 398 (antes caja I, exp. 2), primero de enero de 1930 (en adelante "Escuela Central..."), pp. 24-2.5 


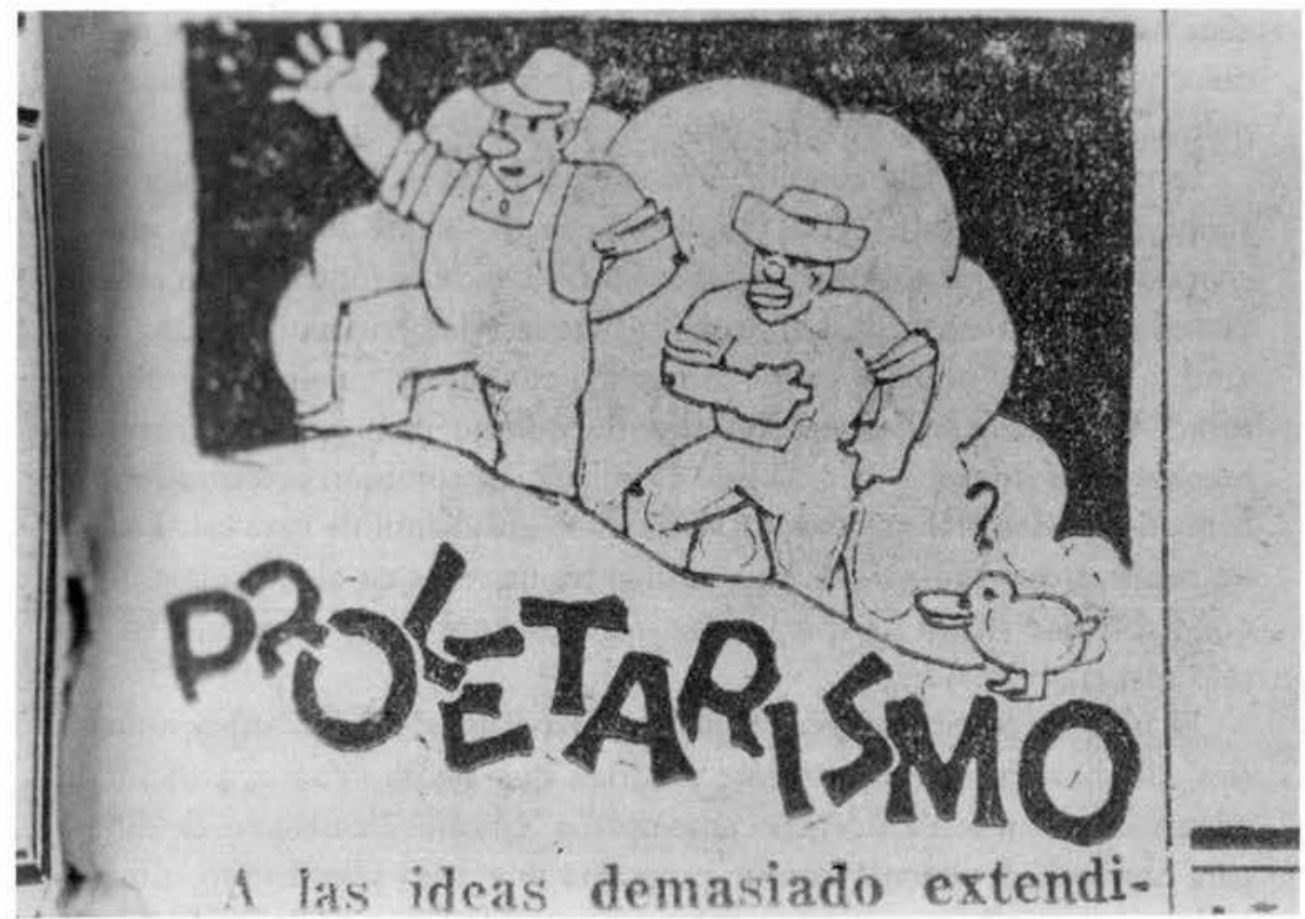

Figura 1. La prensa veia en el plan de Rivera obreros, campesinos... Salvador Pruneda, vin̄eta, en Gustavo Ortiz Hernán, "Proletarismo", en El Nacional Revolucionario, México, 3 de mayo de 1930, p. II-I. Foto: Ernesto Peñaloza, Archivo Fotográfico Manuel Toussaint, Instituto de Investigaciones Estéticas (en adelante IIE).

¿Quiénes eran los proletarios a los que se dirigía el anuncio? Una lectura apresurada podría dar la impresión de que Rivera era perfectamente coherente con las ideas socialistas que había suscrito desde que fundó, con David Alfaro Siqueiros, Xavier Guerrero y otros, el Sindicato de Obreros Técnicos Pintores y Escultores. ${ }^{27}$ Pero a este respecto la realidad fue muy distinta. Es útil comparar el proyecto de Rivera, que se ostentaba como "proletario" y "revolucionario", con los que lo precedieron y con la realidad misma de la Academia.

En el plan de Ramos Martínez, los estudiantes eran admitidos a los "estudios especiales de pintura" mostrando un certificado de "Instrucción Primaria Superior". El de Rivera aumentó ese requisito: exigía secundaria terminada, y los estudios comenzarían con un "ciclo preparatorio" de tres

27. Véase el manifiesto en Antonio Rodríguez, David Alfaro Siqueiros, México, Crea-Terra Nova, 1985, pp. 89-91. 
años para pasar a otro, superior, de cinco. ${ }^{28} \mathrm{El}$ cambio es dramático; de los niños y aprendices de las Escuelas al Aire Libre pasamos a los licenciados en pintura. ${ }^{29}$

Es complemento del anterior el problema de los estudios especiales y los alumnos supernumerarios. Los "supernumerarios" — hoy diríamos oyenteseran estudiantes que tomaban clases sueltas. ${ }^{30}$ Desde su fundación en el siglo XVIII, la Academia se concibió como una escuela de perfeccionamiento artesanal, a la par de su papel rector en materia de pintura, escultura y arquitectura. ${ }^{3 \mathrm{I}} \mathrm{La}$ presencia de estos estudiantes que no iban a ser pintores era muchas veces informal y no ha sido estudiada. La comisión investigadora de la maniobra electoral que originó el conflicto estudiantil de i930 calculó que no había en ese año más de 134 estudiantes inscritos en alguna clase, a los que había que sumar 74 que asistían regularmente como oyentes, ${ }^{32}$ tal vez sólo a las clases de dibujo.

El plan de Ramos Martínez mencionaba a los alumnos "supernumerarios" de pintura, que únicamente tendrían que arreglar con el profesor su asistencia a los talleres. Además contemplaba "estudios elementales de dibujo para obreros", de acuerdo con un programa muy bien planchadito, almidonado y orientado específicamente a sus necesidades: con clases de dibujo constructivo, dibujo de imitación y modelado, exámenes trimestrales y certificados. ${ }^{33}$ El proyecto de Rivera omitía ese modesto curso de capacitación. Aunque señalaba la posibilidad de admitir en las escuelas de talla, fundición, vidriería o grabado a obreros que no hubieran cursado la secundaria, dicho

28. Tibol, Diego Rivera..., pp. 88 y 94

29. Las escuelas de pintura al aire libre pasaron de la ENBA al Departamento de Bellas Artes de la Secretaría de Educación Pública en enero de 1929. Al proclamatse la autonomía universitaria, este cambio de adscripción se hizo definitivo; véase González Matute, op cit. p. I5o. De ahí a la página 154, González Matute narra la decadencia de las EPAL.

30. García, op cit., pp. 43-44.

31. Véase lo dicho por Eduardo Báez Macías, "La Academia de San Carlos en la Nueva España como instrumento de cambio", en Las academias de arte. VII Coloquio Internacional de Historia del Arte, México, Universidad Nacional Autónoma de México, Instituto de Investigaciones Estéticas, 1985 , p 39.

32. Mariano Silva y Aceves et al., "En la ciudad de México..", Cesu, REC, caja 3I, exp. 398 (antes caja r, exp. 2), 5 de junio de 1930, p. 78 Para saber más sobre este problema sería necesario tevisar las listas de inscripciones.

33. "Doce ejemplares del plan de Estudios de la Escuela Nacional de Bellas Artes", CESu, ESC-NAI (FESA), caja 20 (antes 2I), exp. I, 2I de enero de I928, p. 4 
ingreso se haría mediante "concursos especiales" ${ }_{34}$ Cabe ahora mencionar que algunos de los opositores a Rivera eran precisamente profesores de las clases nocturnas de dibujo, a las que asistía la mayor cantidad de supernumerarios y obreros. 35

A pesar de ese aumento en los requisitos, o tal vez precisamente por él, Rivera se esforzó un poco por fomentar la inscripción de obreros. En el archivo histórico de la Universidad se conservan borradores de dos carteles propagandísticos que llaman a los trabajadores a inscribirse para perfeccionar su oficio "por medio de las artes del dibujo". ${ }^{36}$ Además, tenía esperanzas de que los obreros se inscribieran en la escuela para volverse artistas. Durante el acalorado debate del Consejo Universitario que culminó con su renuncia, puso a Mardonio Magaña y a Rufino Tamayo como ejemplo de que los mejores artistas de México "vienen de las clases más pobres",37 a lo que le respondió lapidariamente Guillermo Toussaint:

[...] la academia actual tiene la intención de que asistan obreros como siempre han asistido y yo hago constar que los cursos nocturnos exan exclusivamente para obreros y estos cursos han pasado en su totalidad a la Facultad de Arquitectura $[\ldots . . .]^{38}$

No le faltaba razón. Aunque declaraba que su plan era para "la clase obrera", el obrero del plan de Rivera era un personaje retórico. Es muy parecido al obrero soviético que dirige la revolución mexicana en su mural de la SEP, un obrero moderno. Los "obreros" que siempre habían asistido a la Academia eran artesanos.

Pese a esa contradicción, Rivera trató de explicar el conflicto como un enfrentamiento de clases, en el cual él encabezaba la parte proletaria:

34. Tibol, Diego Rivera ...,pp 88 y 94. En el ejemplar del plan de estudios de 192.8, mencionado en la nota 4, los capítulos de "Estudios para profesores de dibujo constructivo, dibujo de imitación y modelado", así como los "Estudios elementales de dibujo para obreros", están subrayados con lápiz rojo y dicen "si". Esto plantea la posibilidad de que dichos estudios siguieran impartiéndose sin ser mencionados en el plan de estudios aunque, por lo que se ve más adelante, es posible que se hubieran refugiado en la Facultad de Arquitectura.

35. CESU, RSC-NAI (FESA), caja 9, exp 3, 94, 192.6.

36 "Escuela Central..., p. 26

37. "Acta y transcripción taquigráfica...", p. I66

38. Ibidem, p. 215. No he encontrado confirmación alguna de esta afirmación. 
Es muy viejo, en la antigua Academia de San Carlos el antagonismo entre los Alumnos de Arquitectura y los de Pintura y Escultura, debido a que los arquitectos provienen casi sin excepción de la burguesía, y los pintores, escultores y grabadores en casi su totalidad son obreros, campesinos o hijos de éstos, los que no vienen de la pequeña burguesía pobre; así pues, desde antes de mi llegada a la dirección de la Escuela existía en ésta un problema de clases. ${ }^{39}$

Sería difícil negar đel todo esa interpretación. En algún momento del conflicto, el propio rector se presentó en la Academia y percibió la diferencia de clase: "es innegable, basta ver a los unos y a los otros." 40 En uno de sus discursos, Rivera afirmó que los arquitectos "dejaban una estela de perfume" por los corredores. "Entonces se puso de pie el alumno Favela y manifestó que pudiera ser, en efecto, pero que mientras eso acontecía con los muchachos de Arquitectura, con algunos de los pintores sucedía lo contrario, pues en vez de estela de perfume dejaban olor a marihuana, a alcohol y a cola.... "4I

Gustavo Ortiz Hernán, cronista estrella de El Nacionaly enemigo de toda literatura "afeminada", opuesta a la "revolucionaria" y "viril", estuvo de acuerdo con la caracterización: en términos estéticos, la primera guerra mundial había dado como resultado "homosexuales y obreros de buena fe". Pero no se dejó engañar por los overoles de los riveristas:

En cambio, proveerse de actitudes desaliñadas, evitar en lo posible primarias prácticas de higiene, vestir a la pata la llana, es a pesar de todo algo provisto de inminentes significaciones obreristas. Obtener una apariencia proletaria sí es muy fácil... Corbata papillon o ausencia de corbata: en realidad es la misma cosa. Ser homosexual o embutirse dentro de un overol. También es lo mismo. La revolución no está en la apariencia. ${ }^{42}$

Y lo mismo exclamó Lombardo Toledano durante la sesión de mayo del cu, tratando de ver detrás de los disfraces:

39. Tibol, Diego Rivera., p. 100, reproduce declaraciones aparecidas en El Nacional el 26 de mayo de 1930.

40. Ibidem.

4I. "Una protesta contra Rivera", en El Universal, México, 2 de abril de 1930, p. I.

42. Gustavo Ortiz Hernán, "Escaparate", en El Nacional Revolucionario, 2.3 de mayo de I930, p. 3 
Figura 2. Ser proletario era, ante todo, parecerlo. Salvador Pruneda, viñeta, en Gustavo Ortiz Hernán, "Proletarismo", en El Nacional Revolucionario, México,

3 de mayo de I930, p. II-2, Foto: IIE.

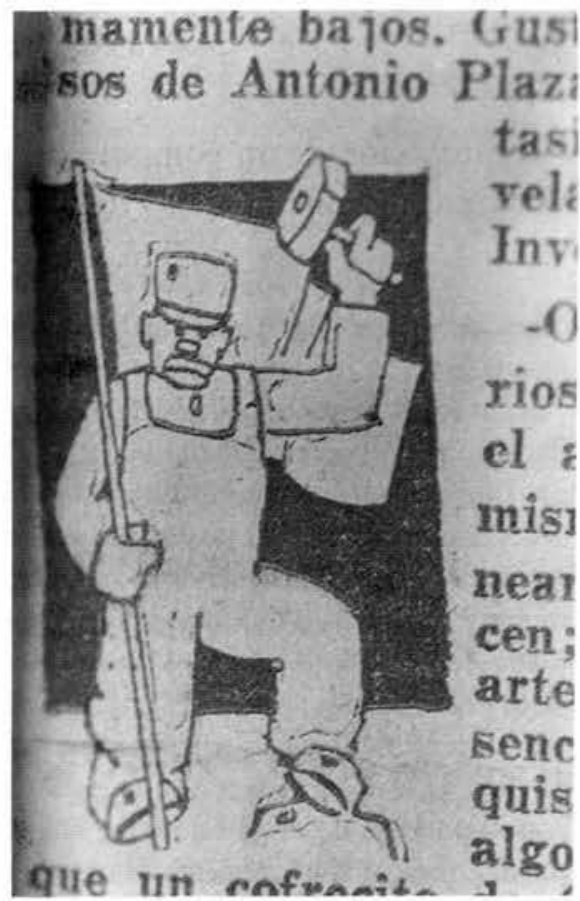

No se trata de obreros y de catrines, ni de arquitectos supuestos ni de pintores falsos; se trata de todo aquel que quiera ir a la Escuela a aprender y que tenga el propósito de hacer un oficio o una profesión; de eso se trata y para eso no hay límites. ${ }^{43}$

En esta universidad de capa y espada, en la que un estudiante retó a duelo a Rivera, ${ }^{44}$ el nuevo director de la ECAP se había opuesto, en octubre de 1929 ,

43. “Acta y transcripción taquigráfica...”, p. 243.

44. El debate provocó niveles muy altos de violencia, pero se trataba de una violencia ritualizada en la que también intervenían los disfraces. Así, en diversos momentos del conflicto, unos estudiantes se presentaron en la rectoría a declarar que habían bañado y le habían lanzado huevos a Abelardo Carrillo y Gariel y que lo volverían a hacer "cien veces" si fuera necesario: "Presentes en la rectoría los alumnos...", cESU, REC, caja 3I, exp. 398 (antes caja I, exp. 2), 1930, pp. 96-97, y "El conflicto de Diego Rivera y los arquitectos", en El Universal, 29 de abril de 1930, p. I. Quizás el conflicto se haya originado porque en el último "bautizo de perros", los pintores habían violado "un compromiso, volcando sobre un grupo de arquitectos un gran bote con pintura": "El lío entre pintores y arquitectos", en El Universal, 3 de abril de 1930, pp. I y 10. En los festejos por el primer aniversario de la autonomía, los propios estudiantes que festejaban lanzaron peligrosos cohetones sobre la multitud reunida: "La autonomía de la Universidad", en El Universal, 27 de mayo de 1930, p. I. Meses después, los inconformes estudiantes de la Academia dieron trabajo a los caricaturistas políticos, apedreando al 
a la aprobación de un pomposo reglamento de las sesiones del Consejo Universitario, que consideraba "rigurosamente obligatorio para todos sus miem-

rector sin compasión: "Cartón del día", en El Nacional Revolucionario, 3 de septiembre de 1930, p. 3

El consejero Favela, estudiante de arquitectura, no tuvo empacho en afirmar ante el cu que "los señores Profesores y alumnos de Artes Plásticas, sin haber profanado los santos salones de esta Universidad, se acercaron a nosotros y nos pidicron nuestra ayuda como estudiantes, para deshacerse de una persona verdaderamente molesta para la conducta de la Escuela y verdaderamente estéril para la marcha de la Escuela": "Acta y transcripción taquigráfica ,", p. 23I. Tal vez fue él quien dirigió un pasquín al Consejo Universitario, antes de que todo empezara, en contta del "panzón Rivera" por "¿comunista, pancista?": "Abajo el director de Bellas Artes", CESU, CON-UNI, caja 26, exp I83, 24 de enero de 1930. Pero la respuesta de Rivera y sus partidarios fue igual de tajante y tampoco se limitó a lo verbal. Al primer conato de pleito, el 26 de abril de 1930, el director impugnado tomó la peligrosa decisión de llamar a la policía para imponer el orden, medida que hubiera sido perfectamente normal durante la década anterior, pero no ahora, a menos de un año de haberse obtenido la autonomía; véase "Fenomenal escándalo hubo en Bellas Artes", en El Nacional Revolucionario, 26 de abril de 1930, pp. 1-2.

Rivera parece haberse dado cuenta de su error y probó el otro camino. En la siguiente sesión del cu, se presentó marchando con una manifestación tras él. Como sus adversarios ya habían tomado posiciones en la sala de sesiones, el ambiente se puso muy tenso: supuestos riveristas agredieron cuchillo en mano al presidente de la Sociedad de Alumnos de la ECAP, Manuel del Castillo Negrete. Poco después, unos policías hostigaron a profesores antirriveristas que cenaban en un café de chinos, llegando a la mismísima impertinencia: "estos señores le preguntaron a la señorita Amparito que quiénes éramos nosotros y que de qué hablábamos." Y aunque sus opositores hacían lo mismo, podían regodearse diciendo: "El señor Diego Rivera capitanea, señores, óiganlo bien, capitanea a una chusma de individuos desartapados que llegaron por esa puerta gritando Viva Diego Rivera.... "Este último fue amenazado más de una vez, e incluso se le retó a duelo. A él le pareció "una ridiculez" el guante lanzado, "un resto medioeval, teatral, bueno tan sólo para la burguesía", pero no dejó de aclararle a su rival que "para un singular combate, forzosa es la semejanza de condición de los caballeros, y no establece la caballería la paridad de las condiciones entre estudiante y director", lo que prueba que no desconocía la patafernalia de semejantes combates. En fin, poco antes de la sesión del 14 de mayo, y por causas que no he podido averiguar, Alejandro Gómez Arias se peleó a golpes con Rufino Iamayo, que a la sazón era partidario de Rivera. Véase "La batalla de pintores y arquitectos", en El Universal, 29 de abril de r930, p. I; "Un 'cuartelazo' a Diego Rivera", en El Nacional Revolucionario, 9 de mayo de r930, p. I-I; "Diego Rivera repelerá cualquier agresión", en El Universal Gráfico, México, 2 de abril de I930, p. 3; "Como acto de disciplina, severo castigo a los que amenazaron a Diego Rivera", en El Nacional Revolucionario, 3 de abril de 1930, pp. I y 7; Diego Rivera, "Diego Rivera contesta a la coalición de estudiantes", en El Universal, 28 de abril de 1930; CESU, REC, caja 3I, exp. 398 (antes caja I, exp. 2), p. I4; "Es fácil la resolución del problema estudiantil", en El Nacional Revolucionario, 27 de abril de 1930, pp. I y 6, y "Acta y transcripción taquigráfica...", pp. I85-186, I93 y 200. 


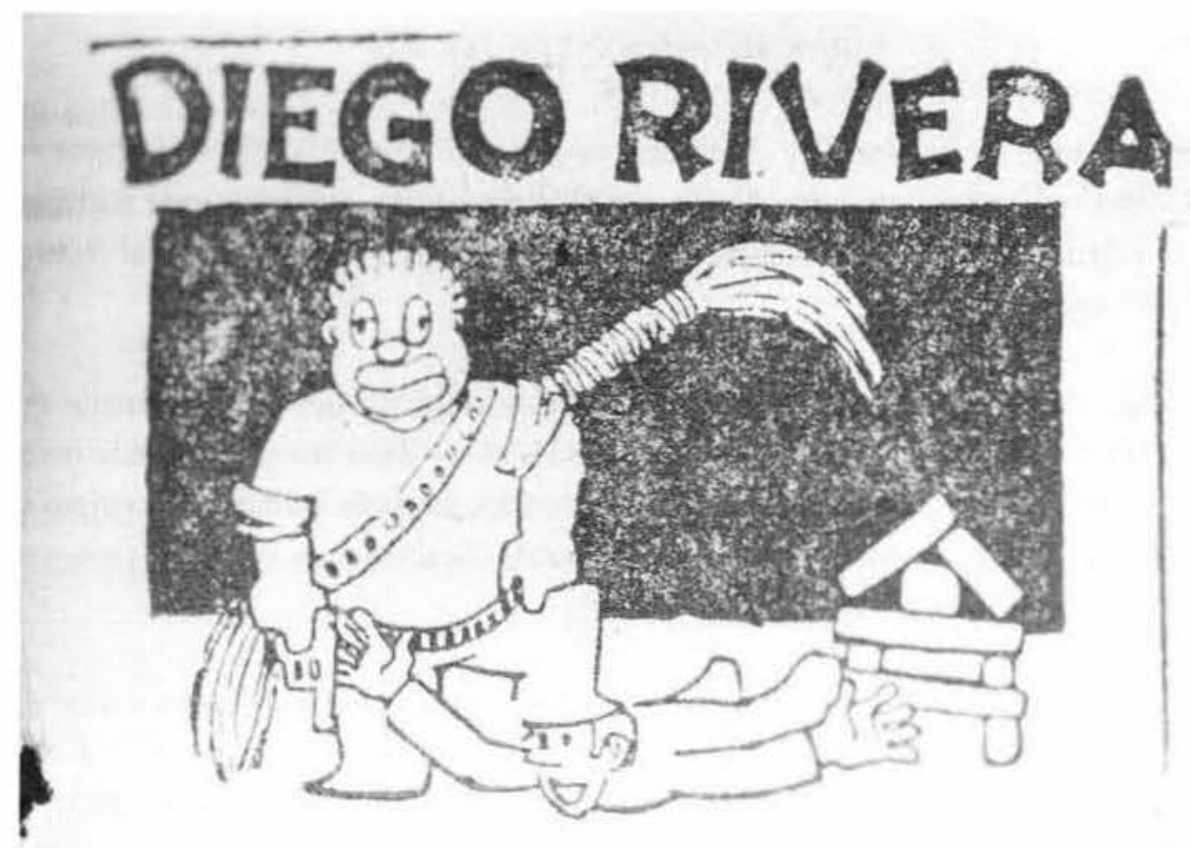

Figura 3. Un estudiante retó a duelo a Rivera. Salvador Pruneda, vin̄eta, en Gustavo Ortiz Hernán, "Diego Rivera", en El Nacional Revolucionario, México, 4 de abril de 1930, p. II-1. Foto: IIE.

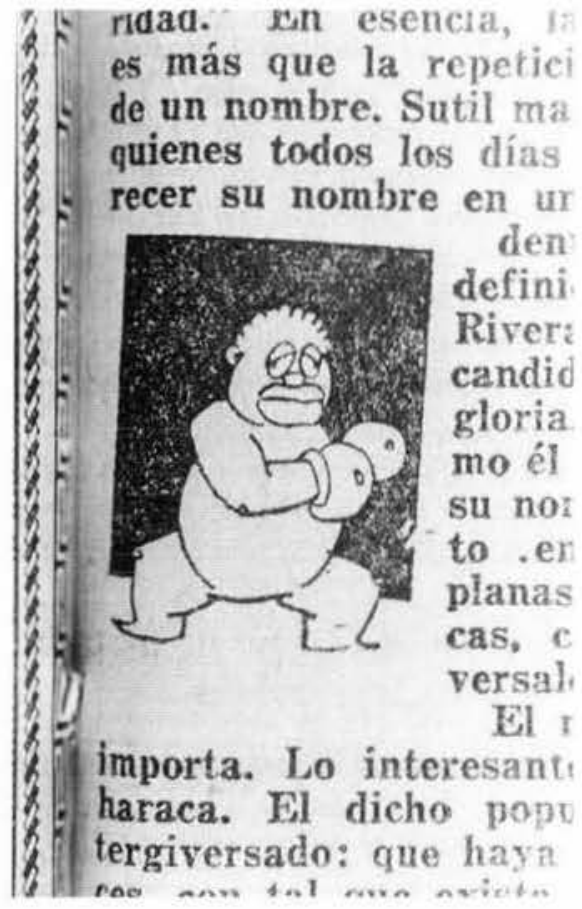

Figura 4. Un estudiante retó a duelo a Rivera. Salvador Pruneda, viñeta, en Gustavo Ortiz Hernán, "Desafios", en El Nacional Revolucionario, México, 27 de abril de 1930, p. II-I. Foto: IIE. 
bros el traje de etiqueta" y establecía el trato de "Señoría" para el rector.45 ¿Cómo, entonces, quejarse de los estudiantes en los términos que lo hizo Lombardo un par de años después, al tenunciar a su largo interinato al frente de la ECAP?

$\mathrm{Al}$ recibir la dirección de la Escuela, había un ambiente que podría llamarse de "chulismo" a la Murguer; privaba, y esto aún no desaparece, la ridícula pose de lo bohemio, sombreros de anchas alas caídas, enormes corbatas de mariposa, estudiantes barbudos y sucios, con cachimbas humeantes en la boca y poses en todo, inclusive en la pretensión de arte. ${ }^{46}$

Esos estudiantes "teaccionarios", "chulos", olorosos a mariguana y a cola, sacaban cada año los disfraces de mosquetero y las armaduras de la bodega, tal vez los mismos que había traído Fabrés tres décadas antes para enseñar la pintura de sus escenas "históricas", y desfilaban montados en elefantes para celebrar el inicio de cursos (véase figura 6), ${ }^{47}$

Al renunciar a la dirección interina de la Academia en enero de 1932, Vicente Lombardo Toledano, "En la Escuela Central de artes Plásticas se va derecho al fracaso", en El Nacional. Diario Popular, México, 27 de enero de 1932, p. I, abundó: "La Escuela va al fracaso, sencillamente porque no ha sido posible cambiarle el ambiente, ni arrancar las raíces del mal; y el mal estriba en que los ingenieros odian a los arquitectos, y viceversa; que los arquitectos odian a los pintores, y viceversa; que los dibujantes riñen constantemente con los grabadores, y viceversa; que los tallistas hacen política a los modeladores, y viceversa; que las modelos no quieren asistir con puntualidad a sus sesiones, y que los estudiantes no las consideran como 'modelos simplemente'; que los estudiantes son muchos y los locales pocos y mal acondicionados; que los arquitectos quieren anrojar del edificio de San Carlos a los pintores y escultores, y éstos arrojar a los arquitectos; y como no ha sido posible tener un edificio para cada una de las ramas de las bellas artes, la pugna, los antagonismos ridículos, inmotivados y todo, continuarán, y el problema con que habrá de enfientarse el futuro director será ése, el del local, que va aparejado con la indisciplina y la abulia de los estudiantes, y luego con la lucha de clases, porque el arquitecto va limpio y bien trajeado a sus clases, mientras que el pintor y el escultot son descuidados en su indumentatia."

45 "Reglamento de las sesiones del Consejo Universitario", CESU, CON-UNI, caja 22, exp. 155,9 de octubre de 1929, pp. 4-6

46. Lombardo Toledano, "En la Escuela...", p. I

47. "Siguiendo la tradición...", en El Nacional Revolucionario, 22 de marzo de 193I, p. III-I, y "Aspecto de la alegre mascarada llevada a cabo ayer por los alumnos de la Escuela Central de Artes Plásticas", en El Nacional. Dianio Popular, 13 de marzo de 1932, p. E. Sobre la parafernalia fabresiana véase Ramírez, "Tradición y modernidad ..", p. 223. 
Figura 5. Diego Rivera se opuso al reaccionario traje de etiqueta. Salvador Pruneda, "Su señoría, el director de Bellas Artes", en El Nacional Revolucionario, México, I5 de octubre de 1929, p. 3. Foto: IIE.

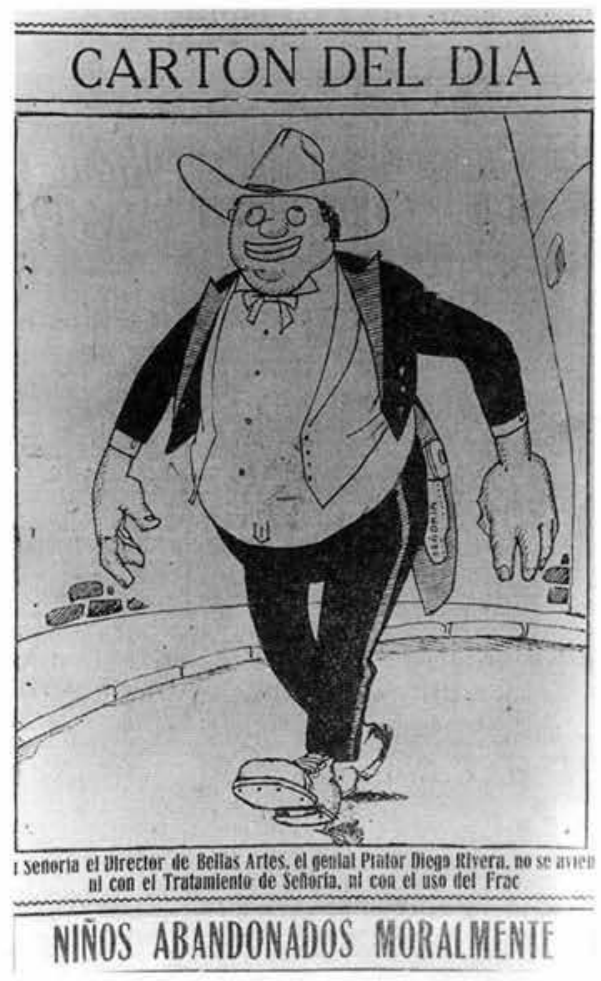

Era ahí, en esa esfera teatralizada, donde se escenificaba una lucha de clases a la que sería difícil calificar tajantemente de ficticia: es muy posible que a veces los disfraces correspondieran a la realidad. Entre los estudiantes, sin embargo, los que se opusieron a Rivera no fueron quienes serían realmente excluidos por el nuevo perfil del estudiante; los que se opusieron fueron los "catrines", como veremos un poco más adelante. Ello se debe a que el conflicto de clases, teatralizado y todo, no era el único problema retórico que se disputaba. El de la "modernidad" tenía quizá la misma relevancia.

\section{Influencia de la vanguardia soviética}

La característica que primero salta a la vista del plan de Rivera es la importancia que concede a la intervención de las artes en la vida, tanto a través del diseño como de la arquitectura. En varias etapas se mencionan "maquetas constructivas" y trabajo con materiales específicos. En el primer año se estudiaría la "aplicación del dibujo y la pintura al oficio manual que ejerza el 


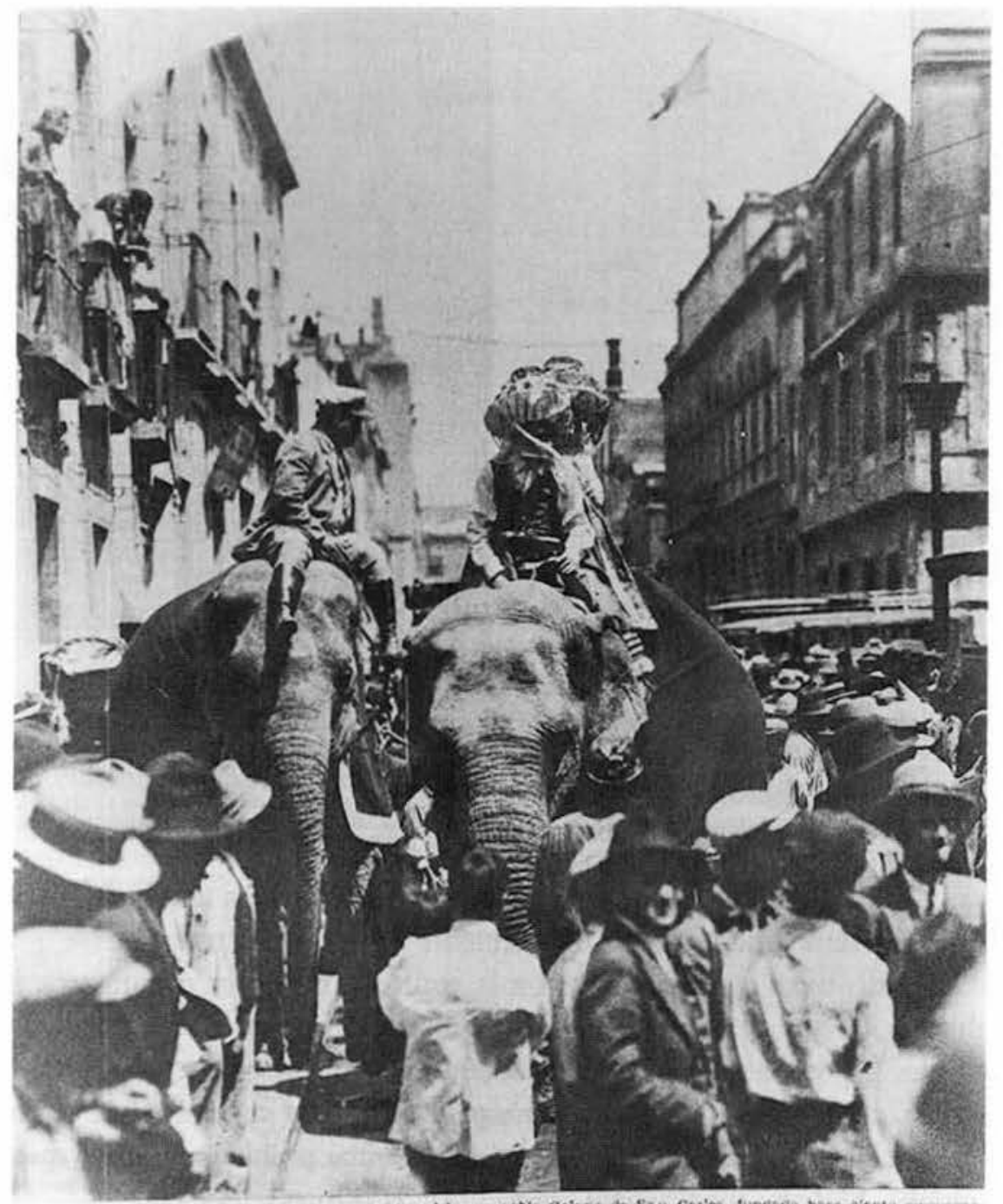

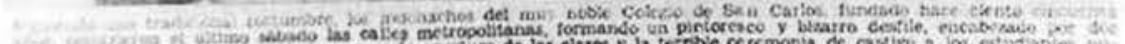

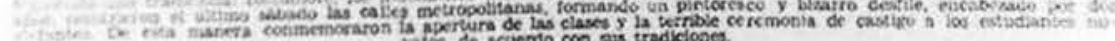

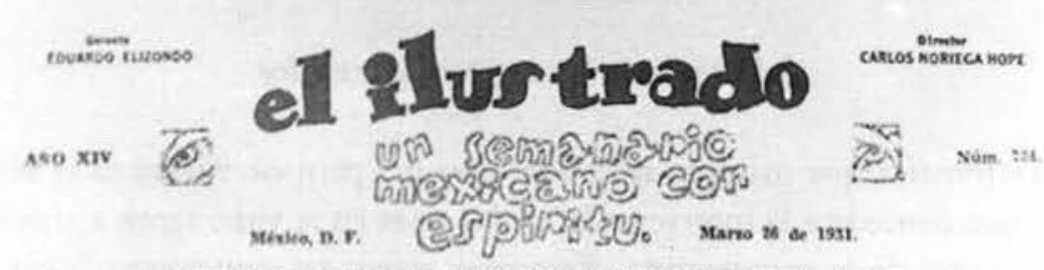

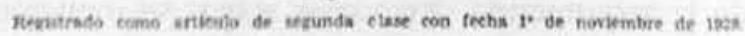

Figura 6. Estudiantes de la Academia desfilan disfrazados. "Siguiendo una tradicional costumbre", en El Universal Ilustrado, México, 26 de marzo de 1931, p. 3. Foto: IIE. 


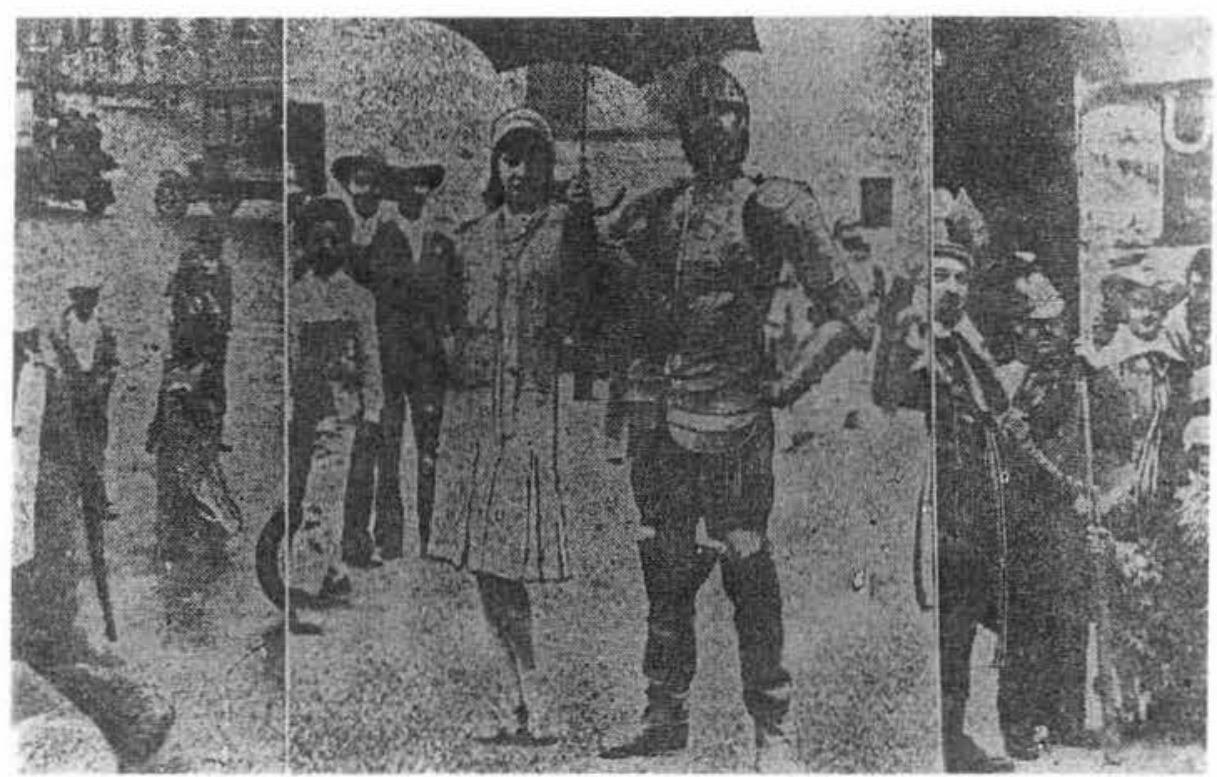

Figura 7. Estudiantes de la Academia desfilan disfrazados. "Siguiendo una tradición...", en El Nacional Revolucionario, México, 22 de marzo de 1930, p. III-1 abajo. Foto: IIE.

alumno" y "el dibujo y la pintura al servicio del embellecimiento de la habitación y el vestido". En el segundo, "problemas del mueble y miembros arquitectónicos, para los cuales será resuelto el problema por el profesor arquitecto". También "se trabajará con temas concretos aplicando la creación plástica a las necesidades de la vida, decoración de interiores y exteriores, objetos de uso, cuadros y dibujos con destino mural y con temas adecuados al lugar a que se los destine, dibujos para ilustraciones de libros y periódicos, carteles y anuncios"..$^{8}$ Rivera entró en pláticas con su amigo Ramón P. de Negri, secretario de Industria, Comercio y Trabajo, para ligar la enseñanza en la Academia al desarrollo de la pequeña industria.49

Lo anterior debe verse como consecuencia del conocimiento que Rivera tuvo de la práctica artística y escolar de la vanguardia soviética durante su viaje a la uRss, entre 1927 y 1928 . Rivera, que firmó el manifiesto del grupo Octubre con los constructivistas, era sensible a sus propuestas. ${ }^{\circ}$ No sorpren-

48. Tibol, Diego Rivera..., pp. 89-93.

49. "Conferencia del señor Diego Rivera", Cesu, REC, caja 29, exp. 386, 25 de octubre de 1929 (en adelante Rivera, "Conferencia..."), p. 10.

50. Richardson, "The Dilemmas of a Communist Artist: Diego Rivera in Moscow, 19271928", en Mexican Studies/Estudios Mexicanos, Irvine (California), vol. 3, núm. 2, invierno de 
de, en vista de lo anterior, que en el "ciclo superior" de estudios de la ECAP se incluyeran "ejercicios creativos de composición elemental arquitectónica sujetos a programas precisos, resueltos enteramente por un arquitecto", así como "elementos de construcción y ejercicios de composición arquitectónica" "sI

Es en este punto donde puede verse la adopción de principios de la vanguardia soviética. A principios de los años veinte, Malevich y Tatlin se esmeraban en independizar a la arquitectura de la simple edificación, en la que había degenerado. Tatlin ofreció una fórmula para la actividad creativa, que llamó "construcción de materiales" que, desde su punto de vista, reemplazaría a la arquitectura tradicional: "Pintura + ingeniería-arquitectura $=$ construcción de materiales." 52

En un artículo que habría aparecido en el número 4 de la revista $330-30 !, 53$ Rivera se burló de los objetos tatlinianos, pero habló con admiración de la atquitectura soviética en términos que parecen consecuentes con los de Malevich y Tatlin:

Se ha establecido la trilogía de materiales realmente ultra-modernos: cemento, hierro y vidrio, y con ellos, se han conseguido expresiones ligeras, fuertes y sencillas que marcan una nueva época en el arte de construir. ${ }^{54}$

Tiempo después explicó a los estudiantes de la Academia: "En realidad el punto mejor a que podíamos llegar en esta escuela, era el punto de que

1987, pp. 58-6r; Alicia Azuela, "Rivera and the Concept of Proletarian Art", en Diego Rivera: A Retrospective, catálogo de exposición en el Instituto de Artes de Detroit, Nueva York, W.W. Norton, 1986, pp. I25-I29, y Olivier Debroise, "Hotel Bristol, Tverskaya 39", en Curare, México, núm 5, 1995, pp. 4-8.

51. Tibol, Diego Rivera,.., pp. 89-93.

52. Anatolii Strigalev, "Nonarchitects in Architecture", en The Great Utopia The Russian and Soviet Avant-Garde, I9IS-I932, catálogo de exposición en el Museo Guggenheim, septiembre-diciembre de 1992, curadora Jane Sharp, Nueva York, Guggenheim Museum, 1992, p. 670

53. Dicho número quedó inédito.

54. González Matute, "Documentos del grupo de pintores i30-30!” (recopilación documental incluida en la caja del catálogo), en ,30-30! contra la Academia de Pintura, catálogo de exposición en el Museo Nacional de Arte, incluye estudio, documentos y folletería, México, Instituto Nacional de Bellas Artes, Museo Nacional de Arte, 1993, pp. 65-67. Por desgracia, no es éste el lugar para referirnos a sus interesantes opiniones sobre el cine y el teatro, que le parecían superiores a la pintura de la uRss 
hubiera una preparación que fuera común para los pintores, los escultores y los arquitectos $[. .$.$] que hubiera una cantidad de conocimientos exactamente$ iguales para todos." 55

En el Consejo Universitario, a los arquitectos les dio desconfianza este detalle y parece que lo criticaron ${ }^{56}$ Rivera dio diversas razones, como la utilidad de ese conocimiento para la pintura mural; $; 7$ pero la desconfianza de los arquitectos era justificada. Al tanto de los proyectos arquitectónicos de los que se pavoneaba el pintor, ${ }^{58}$ debieron olfatear detrás de esas asignaturas sus devaneos miguelangelescos. Debido a la discusión del plan de estudios en el Consejo Universitario, que adivinamos agria, al inaugurar la exposición de estudiantes de artes plásticas, el primero de abril de 1930, Rivera "llamó reaccionaria a la Facultad de Arquitectura porque no ha sabido crear el estilo mexicano en esa rama de las bellas artes" $\$ 9$ y después abundó en la defensa de su proyecto. Primero dijo, tibiamente, que "con ese Plan, no se trata de hacer arquitectos, sino de enseñar a los pintores y escultores la arquitectura que les es necesaria para su oficio". Pero en seguida abundó:

La acción de la Facultad no puede considerarse sino como extralimitación de exceso de celo gremial o ¿por qué no?, deseo de acaparamiento para ella sola de la cultura necesaria a todos los artistas, ya que la enseñanza medular de las artes plásticas, no puede ser sino la misma para todas ellas $[. . .]^{60}$

Como iremos viendo en seguida, a Rivera no sólo le interesaba la arquitectura en relación con la pintura mural, sino también porque su deseo era format artistas que fuesen, en alguna medida, profesionistas útiles. Para ese fin, veía a la arquitectura como origen de todo conocimiento sólido sobre las artes; como si todas hubieran sido, en alguna medida, arquitectura.

55. Rivera, "Conferencia...", p. 8

56. "El lío entre pintores y arquitectos", en El Universal, 3 de abril de i930, p. го.

57. Rivera, "Conferencia...", p. 6.

58. Se pueden ver en Rafael López Rangel, Diego Rivera y la arquitectura mexicana, comentarios críticos de Enrique Yáñez, México, Secretaría de Educación Pública, 1986, passim.

59. "Arquitectos y pintores anduvieron a la greña", en El Nacional Revolucionario, primero de abril de I930, pp. I y 7 .

60. "El lío entre pintores y arquitectos", en El Universal, 3 de abril de I930, p. Io 


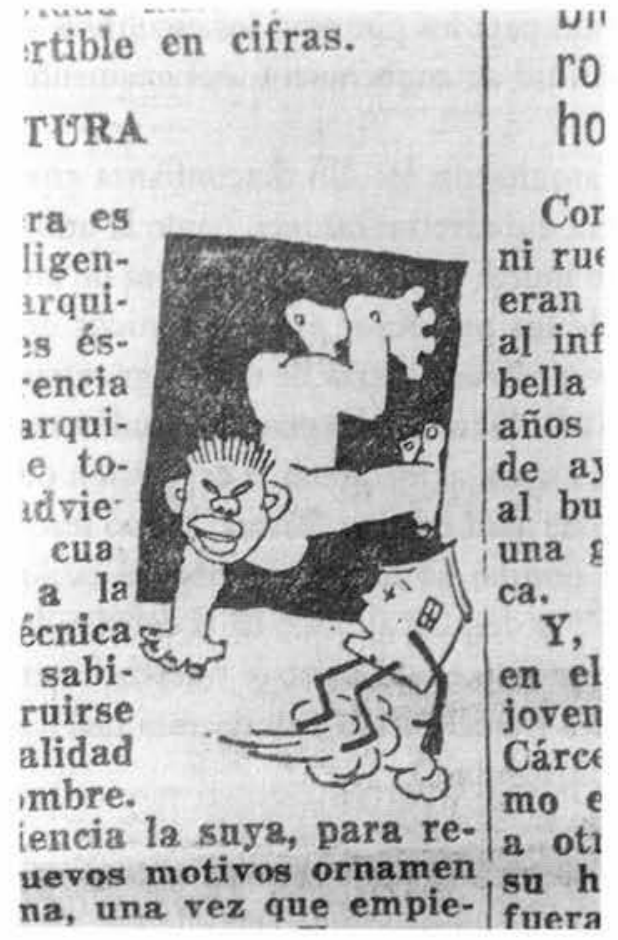

Figura 8. Rivera incluyó materias de arquitectura en su plan de estudios. Salvador Pruneda, viñeta, en Gustavo Ortiz Hernán, "Proletarismo", en El Nacional Revolucionario, México, 3 de mayo de 1930, p. II-2. Foto: IIE.

\section{La restauración de la Academia y la crítica al arte soviético}

Hemos visto algunas características vanguardistas en el proyecto de Rivera; pese a ellas, era marcadamente conservador. Si bien en el bachillerato tenía multitud de asignaturas relacionadas con la "construcción" de objetos, que serían complementadas por las asignaturas arquitectónicas del ciclo superior, en este último el mayor peso de los estudios iba a recaer sobre materias tradicionales. Restauraría la seriación en las materias de enseñanza del dibujo. Ya no habría un taller "libre" con modelo para que todos hicieran sus bocetos con la libertad que recuerda Siqueiros, sino un orden preciso que iría del "estudio superior de la forma en el espacio", empezando por las "formas simples", hasta un "curso superior de perspectiva", que iría acompañado por otro de "mecánica animal". ${ }^{61} \mathrm{Iba}$ a incluir además cursos de mecánica humana, materiales de las artes plásticas, física y química, teoría social de las artes y diversas materias relacionadas con la arquitectura; en los talleres que señalaba 
habría "modelo vivo" y "arsenal de objetos para naturalezas muertas". 62 Uno de sus opositores, Lorenzo Favela, comentó sarcásticamente en el Consejo Universitario:

Es una contradicción en lo que a fines del año pasado, cuando el señor Ramos Martínez estaba en Europa, las Escuelas de Pintura al Aire Libre propusieron un plan de estudios en el sentido de que para ingresar a las Escuelas al Aire Libre se tuviese que hacer el curso de primaria. Entonces Rivera se opuso definitivamente, dado que él quería tuviera la intuición pura y limpia de un año, asegurando que se contaminaba en los Centros de Educación por medio de la educación primaria; posteriormente vino a querer hacer casi enciclopédicos a los $\operatorname{artistas}[\ldots . .]^{63}$

Su observación era justa. Visto en un periodo de tres décadas, contadas desde el inicio del siglo, el plan era termidoriano. Acababa con la importancia que se daba al "dibujo del natural", a la vez que limitaba considerablemente el peso de los talleres libres y la libertad de maestros y alumnos para determinar sus actividades en ellos. ${ }^{64}$ No se hablaba en ningún lugar de "intuición" o "expresión", palabras favoritas del ramosmartinismo; todo en adelante sería rigor racionalista, tanto en su vieja forma académica como en la nueva presentación de sus fríos palacios futuristas. Es bastante claro por qué Rivera se enfrentó a profesores y alumnos de la escuela; no sólo usaba un lenguaje vanguardista para denostarlos, además usaba lenguaje y métodos acàdémicos para acabar con las libertades que habían conquistado trabajosamente. Instauraba la autoridad del plan de estudios sobre los "talleres" o los

62. "Escuela Central ...", p. 28.

63. "Acta y ttanscripción taquigráfica ...", p. 237.

64. Aunque Rivera quitaba peso a los talleres libres en favor del currículum académico, no pensaba abolirlos del todo. Por el contrario, fantaseaba con aumentar su autoridad de una manera que habría disgustado a los profesores y estudiantes que se le oponían: "De manera que la pintura exigirá que el pintor sea de primera calidad o que no pinte; quiere decir esto que habrá nada más uno, dos o tres pintores en un país. Fso quiere decir que exigirá [sic] que los pintores trabajen y así como se juntará la gente para vivir y para trabajar, etc., tendrán que juntarse los artistas para trabajar y tendrá que haber un individuo que sea capaz de componer y los que no sean capaces de componer estatán a sus órdenes", Riveta, "Conferencia ...", p. 6 En "Remitiendo reglamento ante-proyecto academias", CESU, REC, caja 3I, exp. 398 (antes caja I, exp. 2), 9 de abril de 1930, p 33, menciona también la necesidad de fomentar "el docentismo privado sin el cual no hay verdadero funcionamiento universitario posible". 
campings "impresionistas", casi anarquistas a veces, que habían prevalecido durante décadas. No sólo eso: volvía profesión lo que anteriormente se había considerado oficio, consideración sobre la que volveré más adelante.

Las reflexiones de Rivera sobre su experiencia soviética también nos iluminan sobre el conservadurismo del plan. En una conferencia ante los estudiantes de la ECAP, en 1929, afirmó que las escuelas de arte de todo el mundo eran decepcionantes, salvo, quizá, las de Alemania y la unss. ${ }^{65}$ No obstante, el radicalismo de estas últimas le era antipático: "La juventud del Soviet estaba tan exaltada que hubo muchísimos que querían cerrar los talleres y algunos hasta las exposiciones y fueron más allá de lo debido." 66 Más aún: en un artículo que habría aparecido en el fallido númeto 4 de ;30-30!, afirmó:

Los estetas burgueses ultra-modernos admiran la belleza de los puentes, los silos y los aeroplanos y se esfuerzan en limitarla [sic] en sus producciones inútiles y no lo consiguen, porque ignoran que la causa de esa belleza depende precisamente de su utilidad, considerada ésta no en un terreno de apreciación moral; sino de la función de un objeto creado. Por eso mismo el teatro, el cinematógrafo y la arquitectura soviéticas, contienen en toda su fuerza y pureza, la belleza de los altos hornos y las máquinas generadoras de energía, mientras la producción capitalista llamada ultra-moderna, sólo consigue reflejar, queriendo parecerse a un aeroplano, el interés que puede tenet la tienda de un ropavejero y el cajón de la basura. Como esas dos cosas el actual arte burgués, sólo es material de deshecho, que sólo puede volverse útil se le emplea, después de transformarlo, para una nueva producción. ${ }^{67}$

La crítica de Rivera apuntaba hacia los orígenes del constructivismo ruso en la convicción de que el "gusto" y la "composición" eran formas de "psicologismo" anacrónico e individualista ${ }^{68}$ Fue una crítica dura: dijo que la

65. Rivera, "Conferencia ..", p. 4

66. Ibidem, P. I. Aunque quizá con argumentos menos pudorosos y discretos, los constructivistas rusos también estaban en plena retirada hacia el diseño gráfico cuando Rivera los conoció, según lo afirma Cristina Lodder, El constructivismo ruso, Madrid, Alianza, ig88 (Alianza Forma), p. 2.00. En su resumen de la historia de los vkhuremas, Talleres Superiores Artísticos y Técnicos del Estado, queda muy claro que también en esas avanzadas escuelas de arte había secciones tan conservadotas como para enseñar dibujo del natural y dibujo de imitación. Ibidem, pp. II2, I24 y 129.

67. González Matute, "Documentos ... ", pp.. 65-677.

68. Lodder, op cit., pp 91 y 108-7109 
vanguardia soviética fracasó en sus ensayos de "construcción" y que sólo consiguió imitar el aspecto de las cosas útiles, pero no diseñar cosas útiles.

El terreno del arte representativo, tanto de la vanguardia como del que luego sería "realismo socialista", también provocó su crítica. A los líderes bolcheviques, "verdaderos mártires y verdaderos sabios [...] les gustaba la mala pintura, la pintura falsamente realista." 69

También sucede que el proletariado había recibido como educación estética pictórica los productos más inferiores del orden burgués, no encontrándose preparado, se indigestó con los platos complicados y exquisitos de la cocina pictórica ultra-moderna con que se le atiborró en los días del comunismo de guerta, y por reacción natural ha vuelto sus ojos a la pintura académica que por lo menos se le ofrece legible y con asuntos que tocan a sus intereses de clase $[\ldots]^{70}$

En el mismo sentido, señalaba que los carteles revolucionarios soviéticos habían terminado por cansar a los obreros, según le había asegurado uno de ellos:

Porque en el club, se nos habla y nos enseñan estas cosas; en el taller, en las reuniones, en el trabajo cultural de los domingos igual cosa; hombre, en nuestra casa queremos otra cosa porque a nuestras casas llegamos tan cansados del trabajo y del estudio que necesitamos una cosa que nos haga descansar. ${ }^{\text {T }}$

Algo semejante veía en México: el gusto de la clase obrera, de los trabajadores propiamente dichos, le parecía deplorable:

Esto se debe a que el obrero, en primer lugar, tiene el gusto perfectamente burgués: ve todos los anuncios que hay en la calles; en segundo, que todos los domingos ve las secciones de los periódicos, ve todos los malos cuadros de los escaparates $[\ldots . .]^{72}$

69. Ibidem, p. I3.

70. González Matute, "Documentos...", pp 65-67. Véase también Rivera, "Conferencia ....", p. 13 .

7I. Ibidem, p. I2

72. Ibidem, p. Io. 
La impotencia del arte de vanguardia frente a la supervivencia de las formas decimonónicas de pintura lo hacía defender la validez de la pintura mural. Quizá sus amigos soviéticos le hicieron comentarios sobre lo anacrónico de tal género, pero lo importante es que en la urss se estaba imponiendo una pintura de aire decimonónico, y

siendo el arte y con consecuencia la pintura un arma poderosísima en manos de la clase que ejerce el poder, no puede el proletatiado usar de un arma que data de la pequeña-burguesía de Luis Felipe. ${ }^{73}$

Rivera no podía concebir esa utilidad del muralismo sin el estricto y denso plan de estudios propuesto: desde la copia de objetos hasta la perspectiva; desde la anatomía hasta la mecánica animal. Todas ellas eran un dique contra la abstracción porque ésta, siendo un exceso de la vanguardia, propiciaba la reacción conservadota que mencionamos artiba. Rivera no concebía la pintura revolucionaria sin la figuración: "el tema es para el pintor lo que los rieles son para una locomotora." 74 Esta necesidad de justificar la pintura para las masas, frente a una vanguardia estética radical, lo impulsó a formular dos propuestas de renovación en los dos niveles que hemos visto: el de los objetos y el de la arquitectura.

En el primero, postuló la innovación de las artes gráficas mediante el aprovechamiento de la nueva tecnología. En su conferencia ante los estudiantes de la ECAP dijo que la nueva gráfica industrial "multirreproducible" era superior al grabado tradicional.

Es por allí por donde tendrá que ir la producción a la casa del obrero y del campesino, sobre todo, porque no cuestan casi nada y tienen la misma belleza que tiene un cuadro; una buena estampa tiene la misma belleza que puede tener una pintura al óleo, a color o a la acuarela. Es superstición creer lo contrario. ${ }^{75}$

73. González Matute, "Documentos...", pp. 65-67. Véase también Rivera, "Conferencia ...", p. I3. Debroise, op cit, p. 8, reproduce una carta indignada de Rivera a los editores de la revista soviética Revalución y Cultura, donde los argumentos son los mismos. La carta mostraba su acuerdo con los puntos de vista de los attistas de la Asociación de Artistas de Rusia Revolucionaria, pero no así con los resultados, con el "estilo" de la obra de dichos artistas

74. Diego Rivera, "La revolución en la pintura", citado por Moyssén, op cit., p. 138 .

75. Ibidem, p. 2. Aquí también es visible la reflexión sobre los carteles de El Lissitzky, Vesnin y Klutsis. 
Los artistas mexicanos llevaban años quejándose de los cromos industriales de santitos, que competían con su arte mural en el gusto de los desheredados; era llegado el tiempo de usar sus propias armas para vencerlos.

En el segundo nivel, el de la arquitectura, Rivera propuso la utilización de materiales nuevos para la pintura mural, de manera que ésta fuese armónica con las construcciones modernas:

Ustedes se pueden imaginat un edificio moderno, como lo conciben los arquitectos; pero no se puede hacer, todo el mundo lo concibe, con sus grandes paños de cristales, un gran muro por su parte exterior, dentro de la ciudad; pues imagínense la distribución [....] no podemos imaginar más que una gran pintura, una pintura hecha al fresco, en mosaico, o hecha en otros procedimientos que se empiezan a estudiar; ya se empieza a encontrar un procedimiento para pintar, a base de silicato de sosa que permitirá pintar sobre el cemento y va a encontrarse también otros procedimientos para aplicar la pintura a la construcción del concreto y aún de mosaico. Era lo que señalaba Juan Romo, que era mejor que el fresco; pero ésto basta. ${ }^{76}$

Ambas propuestan han sido atribuidas a Siqueiros porque Rivera no las reivindicó más; no lo hizo en sus declaraciones, en sus escritos ni en su obra. Ignoro a qué pueda deberse ese arrepentimiento. (La actitud de Siqueiros, por otro lado, no debe considerarse un plagio: no olvidemos que hicieron juntos el viaje a la uRss.)

\section{La clase obrera no va al paraiso, va a la preparatoria}

El conflicto de la Academia tiene una dimensión política que también veremos en este texto, peto para comprenderlo conviene detenetnos un poco más en las ideas y las contradicciones del proyecto tiveriano. Por más que proclamara su propósito proletario, y que nosotros podamos creer sus buenas intenciones, la academización del nuevo plan de estudios seguramente habría

76. Ibidem, p. 6. El pártafo citado contiene ideas semejantes a las que después expresó Siqueiros sobre el mismo asunto. No debe concluirse, sin embargo, que fue Rivera quien tuvo la ocurrencia de usar nuevos materiales: del texto se desprende con toda claridad que esa preocupación era generalizada. 
excluido a los obreros que asistían a las clases de dibujo desde tiempo atrás. A Rivera ya no le preocupaba la deshumanización del trabajo industrial que denunció Ruskin y que influyó en sus viejos amigos del Ateneo de la Juventud, particularmente en Jesús T. Acevedo. "77 Ahora soñaba con fábricas y ciudades modernas. La utopía romántica actualizada por el colonialismo quería remitirse a una edad anterior; de ahí su desdén por el currículum académico. La utopía riveriana era la descripción de un futuro tecnificado y progresista, en el que los artistas tendrían un lugar a condición de que se convirtieran en algo más: en profesionistas transformadores del entorno. El plan de Rivera, dirigido a los "obreros", se propuso hacerlos cursar la preparatoria para volverlos una suerte de ingenieros en arte que mejoraran estéticamente la vida material de sus hermanos de clase. ${ }^{78} \mathrm{La}$ formulación de ese bachillerato especial coincidía con un propósito del Estado y es posible que respondiera a sus designios. ${ }^{79}$ En octubre de 1929 se había discutido en el Congreso de la Unión una nueva ley de profesiones que daría al Estado la facultad de avalar los títulos profesionales expedidos por las universidades, a la vez que proponía el trabajo obligatorio: "Todo ciudadano capaz está obligado a aprender

77. Véase Jesús T. Acevedo, Disertaciones de un arquitecto, México, Instituto Nacional de Bellas Artes, 1967

78. Debe mencionarse un antecedente de lo anterior. El doctor Atl, durante su fugaz paso por la dirección de la Academia, había querido convertirla en "un taller adaptado para la producción, como cualquier taller industrial de hoy en día, o como los talleres de arte de todas las épocas en que el arte floreció vigorosamente", Charlot, op. cit., p. 70 . No es muy probable que Rivera conociera detalladamente esta experiencia (el libro de Charlot es una historia basada en fuentes primarias que no necesariamente refleja el saber común o la memoria de los artistas), pero, en cualquier caso, lo que es de resaltarse es el sustrato común que alimentó esos y otros proyectos académicos: la convicción, cara a los positivistas, de que el conocimiento debe tener consecuencias prácticas para la evolución nacional. Por otro lado, cabe mencionar que también en los vkhuı EMas existía una "facultad de los trabajadores" independiente, un lugar donde los trabajadores serían capacitados para inscribirse en los Talleres Superiores. Véase Paul Wood, "The Politics of the Avant-Garde", en The Great Utopia: The Russian and Soviet Avant-Garde, I9I5-1932, Nueva York, Guggenheim Museum, 1992, p. 13.

79. "El lío entre pintores y arquitectos", en El Universal, 3 de abril de 1930, p. IO. Si se le hubiera sugerido exigir el bachillerato como requisito para ingresar a la ECAP, Rivera pudo haber supuesto que era preferible mantener como requisito sólo la secundaria y encargarse del bachillerato en la academia misma, proporcionando en los primeros tres años los estudios que consideraba esenciales. También es posible que Rivera mismo quisiera que su plan se adecuata al discutso estatal Setá muy difícil dilucidar de quién fue la iniciativa si no se localizan las minutas de la discusión del plan de estudios 
un oficio, arte o profesión y a ejercerlo en la república un año por lo menos." Para Lauro Caloca, principal promotor del proyecto, la razón principal del mismo era que "la juventud tiene que pensat como nosotros pensamos". Este propósito "revolucionario" era opuesto al romanticismo universitario, al mesianismo vasconcelista, que era visto con hostilidad en las esferas oficiales (y referido con desprecio en su retórica) por la reserva política que brindaba a la oposición. ${ }^{80}$

No se puede menos que pensar en el positivismo clásico frente a este sueño de convertir a la actividad estética, "metafísica", en una acción social. Es como si Rivera hubiera pretendido enderezar el plan vasconceliano de estetizar el "tercer estado". ${ }^{81}$ Resulta significativo que diera precisamente al bachillerato que creaba su plan de estudios la tarea de sustituir la ideología humanista en las artes por esta nueva ingeniería social y estética, como antaño había sido el bachillerato donde se había realizado una operación análoga para terminar con el viejo pensamiento humanista eclesiástico. No estoy diciendo que Rivera hubiese leído a Comte o a Spencer. Lo que importa aquí no es la historia de las ideas, sino la telación de los intelectuales con el poder, o incluso su inserción en el mismo. En esta esfera, algunos tópicos del positivismo brindaron un andamiaje retórico para que la acción de Rivera fuese

80. Véase al respecto "Debe ejercer el Estado el control de las profesiones", en El Nacional Revolucionario, 3 de octubre de 1929; "Un segundo proyecto de ley reglamentaria", en ibidem, 4 de octubre de 1929; Arellano Martínez, "Qué profesiones necesitan título", en ibidem, s de octubre de 1929, y "Fue rechazado el trabajo material obligatorio", en ibidem, I2 de octubre de r929 Cabe aclarar que el rechazo fue temporal, pues actualmente sigue vigente una ley de servicio social que coincide en su espíritu con las intenciones del "trabajo obligatorio"

8I. Mauricio Tenorio, "A Tropical Cuauhtémoc: Celebrating the Cosmic Race at the Guanabara Bay", en Anales del Instituto de Investigaciones Estéticas, vol xv, núm. 65, 1994, p. I29, también señala aspectos en que las ideas de Vasconcelos se sobrepusieron a las del positivismo sin necesidad de tefutarlas; especialmente en lo que se refiere al uso de la categoria de "raza", Asimismo, señala que los orígenes de la imagen de México que se estaba construyendo pueden encontrarse, quizás antes del pensamiento positivista, en el "patriotismo" criollo. Sobre el renacimiento del positivismo en los años treinta véase el periódico del partido gobernante, $E l$ Nacional, durante los años treinta y cuarenta (la llegada al poder de Miguel Alemán cambió evidentemente las cosas). Pueden verse especialmente los artículos de Agustín Aragón Leyva, publicados entre 1931 y 1937, que fue el más explícito, incluso vociferante, neopositivista, pero de ninguna manera el único. Sobre las particularidades del "positivismo" mexicano en el siglo XIX, véase Charles A. Hale, La transformación del liberalismo en México a fines del siglo XIX, México, Vuelta, I99I (La Reflexión). Hale es quien señala el lugar ocupado por el positivismo en la retórica liberal del estado porfiriano. 
coherente con la del Estado. En tanto que funcionario, las propuestas de Rivera y su crítica al humanismo voluntarista de la UNAM estaban de acuerdo inequívocamente con la retórica gubernamental y no con la retórica universitaria, lo que fue determinante para su mala fortuna en el conflicto. Por si hicieran falta más pruebas de lo antetior, en la sesión del I4 de mayo Rivera lanzó una dura crítica a uno de los propósitos más importantes de la UNAM, heredado del mesianismo del Ateneo de la Juventud: la extensión de la cultura. La UNAM quería ser popular,

[....] pero acercarse al pueblo no quiere decir tener una actitud filosófica de marcada simpatía hacia el pueblo. El fundar Escuelas para enseñar a leer a las gentes es magnífico; el enviar misiones al interior del País, de estudiantes, es más que magnífico, es excelentísimo; peto hay algo más que la universidad necesita hacer; ese algo más es orientar no sólo su extensión universitaria, no sólo los aprendices que ella lanza entre la masa del país, sino su organismo mismo. ${ }^{82}$

No menos significativo es el cambio ocurrido, ese sí, en el pensamiento de Rivera. Años atrás, se había adherido al Manifiesto del Sindicato de Obreros Técnicos Pintores y Escultores (sOTPE), donde se decía:

Todo lo que es trabajo noble, todo lo que es virtud es don de nuestro pueblo (de nuestros indios muy particularmente) [....] El arte del pueblo de México es la manifestación espiritual más grande y sana del mundo y su tradición indígena es la mejor de todas. ${ }^{{ }^{8}}$

Ese socialismo bien intencionado y romántico había cedido paso a una nueva concepción. En sus conferencias y pláticas a los estudiantes, Rivera se nota bastante compenetrado con la retórica matxista bolchevique, en la que las bellas razas productoras de belleza no tenían lugar. El mundo del futuro sería para los obreros, pero no en su condición actual, sino apropiados de los conocimientos que permitieran a su clase dirigir la marcha de la historia. Para establecer un paralelo con su pintura, la época del sotpe corresponde bastante bien a los frescos de la planta baja de la Secretaría de Educación, donde "clase" y "raza" son categorías análogas (lo que no podría ocurrir en

82. "Acta y transcripción taquigráfica...", p. I67.

83. Rodríguez, op cit, p 90 
un discurso marxista): los "obreros" son recios, morenos y trabajan en industrias rudimentarias. En cambio, los frescos del tercer piso, realizados poco después de su retorno de la URSS, en I928, muestran a un obrero rubio y vestido como obrero, de dril o mezclilla, siempre con una estrella roja como insignia, dirigiendo la socialización de las actividades productivas en una fábrica moderna. Decir que Rivera pasó de su propio "socialismo utópico" a un "socialismo científico" igualmente sui generis sería correcto, a condición de que no perdamos de vista la adecuación de esa nueva iconografía al discurso oficial mexicano, que también había guardado en un cajón el romanticismo liberal para entrar de lleno en la nueva época de ingeniería social que daría progreso a México.

\section{La discusión del plan de estudios y las generaciones}

Lo anterior parece llevarnos, casi naturalmente, a una explicación "generacional" del conflicto. La idea parece atractiva porque, a fin de cuentas, en el Consejo Universitario la mayoría de los estudiantes y de los profesores jóvenes estuvieron con los inconformes, incluyendo a Lombardo Toledano, en tanto que Antonio Caso y el rector se pusieron del lado de Rivera. La realidad no fue sin embargo tan simple: también había un bando riverista entre los estudiantes de pintura, que incluso se organizó en un sindicato dirigido por Ignacio Márquez. Después de la salida de Rivera, este organismo consideró seriamente abandonar la ECAP para fundar una Escuela de Artes Plásticas en la Universidad Obrera y Campesina, una escuela de cuadros recién creada por el gobernante Partido Nacional Revolucionario. ${ }^{84}$

Alejandro Gómez Arias, que quizás haya leído el famoso ensayo de Ortega y Gasset sobre las generaciones, ${ }^{85}$ siempre planteó el conflicto en términos

84. "Continuará la agitación dentro de la Escuela de Artes Plásticas", en El Universal, 27 de mayo de 1930, p. I. Márquez, junto con Abelardo Ávila, era el dirigente de la sociedad de alumnos depuesto por la inscripción masiva de los arquitectos. Véase "Brotes de agitación entre estudiantes", en El Nacional Revolucionario, 24 de abril de 1930, p. I; panfletos de estudiantes riveristas en "AA los estudiantes del Distrito Fedetal; trabajadores de México!", CEsu, REC, caja 3I, exp. 398 (antes caja I, exp. 2), 1930, pp. 15-16, y "Los estudiantes defienden la labor de Diego Rivera", en El Nacional Revolucionario, 4 de mayo de 1930, p. i-I.

85. Enrique Krauze, Caudillos culturales en la Revolución mexicana, México, Siglo Veintiuno-Secretaría de Educación Pública, 1985, pp. 219-228, analiza el impacto del ensayo de José 
generacionales. Ante la propuesta de nombrar director a Rivera, dijo que los estudiantes habían pensado primero que se nombrara a "un joven", como Julio Castellanos, y además declaró que en su juicio habría sido preferible "un pintor fuerte, por ejemplo Orozco, que dentro de mi humilde pensar es el pintor más grande que tiene México en estos momentos " 86 Pero Rivera, "profundo agitador" como en las "novelas rusas", ${ }^{87}$ también tenía lo suyo y a Gómez Arias, joven león literario, ya le andaba por soltar la pluma para arrancar al pintor un pedacito de aura:

Yo siento no poderme esperar cien años para opinar sobre el señor Diego Rivera y me reservo este derecho para emplearlo en su oportunidad y abordarlo tan profundamente como lo han hecho las personas que se han expresado anteriormente en favor del señor Diego Rivera ${ }^{88}$

Así que pedía "a los consejeros alumnos que asisten a esta sesión, den su voto en favor del señor Diego Rivera" " 89 Nueve meses después su opinión sobre Rivera había variado, pero su retórica no mucho. Argumentó que Rivera no había estado a la altura de farol para la juventud que se esperaba de él:

Hay una cosa particular y excepcional en todo maestro, y en tanto que no la tiene no es maestro, y en tanto que en mayor grado la tiene es más Maestro: es esto la actitud de convencimiento. El Supremo Maestro, todos los saben, es el que convence con su vida limpia y con su palabra; por eso en tanto que se acerca más a este convencimiento perfecto se es más Maestro, y nosotros llevamos a la escuela de Artes Plásticas a Diego de Rivera [sic], no para imponerlo con medidas políticas, sino para imponerlo con su deslumbrante personalidad de pintor; porque sabíamos que no habría escisión; porque sabíamos que Diego dentro de

Ortega y Gasset, "I.a. idea de las generaciones", en Manuel Gómez Morín y en Daniel Cosío Villegas, quien en uno de sus textos de los años veinte llegó a exclamar: “iptoclamémonos generación!"

86. Ibidem, p. $5 \mathrm{I}$

87. Ibidem, p. 52-53." John Skirius, José Vasconcelos y la cruzada de 1929, México, Siglo Veintiuno, 1978 (Historia), p. I44, sugiere que el vasconcelista Germán del Campo tenía en mente a Sachka Yegulev como modelo de sus actos.

88. "Papeles de la sesión de Consejo Universitario del I4 de agosto de I929", CESU, CONUNI, caja 20, exp. I47, I4 de agosto de I929, p. 5I.

89. Ibidem. El subrayado es mío. 
la Escuela, bastaba con su presencia para que la Escuela se convirtiera a las modernas teorías; pero, desgraciadamente, señores, esto no ha sucedido,.$^{90}$

En esa sesión del I4 de mayo de 1930, Gómez Arias fue quien pronunció las palabras decisivas. Pesaba sobre el cu la amenaza de renuncia de Antonio Caso, muy difícil de digerir para la mayoría de los consejeros, que se dirigían a él como "maestro". El joven tribuno y líder estudiantil estaba en un aprieto: ser fiel al dictamen de la Comisión y a la Federación Estudiantil, o acatar sus sentimientos, los de la mayoría, y someterse a la amenaza de Caso. Resolvió el casito con una muy brillante, original y atrevida pieza oratoria que en ningún momento dejó de plantear el conflicto en términos generacionales:

—Caso — reanudó el orado- - aunque se retire no se irá. El magisterio cobra su tributo; y si se fuere, dejaríamos vacante la sede de Filosofía y Letras mientras el maestro viviese! (aplauso estruendoso).

Yo vi cómo esa mandíbula saliente, cual quilla de un barco victorioso, rompía la tiniebla en mi espíritu. Así seguiré haciéndolo mientras viva, y, cuando muera, lo envolveremos en la bandera inmarcesible, en la bandera sacrosanta que tiene el lema universitario inscrito, el lema de la huelga, para que su cuerpo baje al sepulcro. Mientras tanto, Antonio Caso, con su mandíbula saliente, como la quilla de un barco invicto, proseguirá rompiendo la tiniebla de la de México [....]

Indescriptible escena siguió a esas palabras. El maestro Caso lloraba. Chico Goerne apenas podía contener las lágrimas y fue el ptimero en lanzarse a abrazar al viejo filósofo. Todos los consejeros se pusieron en pie como movidos por un resorte eléctrico y se echaron en brazos del luchador del pensamiento que, conmovido hasta lo más profundo de su ser, se había transfigurado. ${ }^{91}$

90. "Acta y transcripción taquigráfica...", pp I98-I99.

9I. "Renunció a la dirección de la Escuela ...", p. 7. La versión taquigráfica de la sesión, en "Acta y transcripción taquigráfica...", p. 260, difiere un tanto de la crónica periodística: las palabras de Gómez Arias suenan menos brillantes y falta la comparación de la mandíbula de Caso con la quilla de un barco. Quizás el cronista de El Nacional Revolucionario se emocionó e imaginó un discurso ligeramente más bonito que el verdadero; prefiero, sin embargo, pensar que el tedio de los taquígrafos del cu se desquitó de las latgas alocuciones de los consejeros, opacando sus palabras sistemáticamente 
Cuando el dictamen que suspendía en sus funciones a Rivera estaba por aprobarse, éste renunció. No así Caso, "pues la emoción lo abrumaba, después de aquella consagración en vida". ${ }^{22}$

Generaciones, sí... pero no tanto. Las "generaciones" no estaban pensadas para incluir, sino para excluir, y no debemos equivocarnos interpretándolas de manera contraria. No había "generación" que uniera a la élite de los pintores, estudiantes o no, con la élite universitaria y política. En la sesión del I4 de mayo, el estudiante rivetista Agustín Villagra se quejó amargamente de la indiferencia de la Federación Estudiantil hacia la Academia e hizo este tevelador teproche:

Los alumnos en su mayoría los que han pasado por la Preparatoria se conocen, mientras que los de Bellas Artes no somos conocidos de los de ottas Escuelas y los de la Facultad de Arquitectura todos lo son, se conocen y son amigos y de aquí ha venido ese grave defecto. ${ }^{93}$

Así era: como ya hemos visto, era posible que los estudiantes de la ECAP no hubieran pasado ni siquiera por la secundaria. Se explica ahora, mejor que nunca, el conflicto estudiantil estrictamente: Manuel del Castillo Negrete, presidente de la Sociedad de Alumnos impuesto por los arquitectos, era estudiante de pintura pero sí había pasado por la preparatoria e incluso había cursado algunos años de derecho. ${ }^{94}$ También él, a diferencia de Márquez, había sido alumno de Caso, lo que lo hacía proclive a la "generación" y no al "sindicato".

\section{La autonomía}

La explicación generacional fue, posiblemente, la que prevaleció entre la mayoría de los consejeros universitarios. En el interior de la Universidad

92. Ibidern

93. Ibidem, pp I90-I9I.

94. Castillo Negrete era el presidente de la Sociedad de Alumnos, que lo hizo delegado ante el CU. Se le menciona como tal en todas las actas del mismo posteriores a los hechos ya narrados y, además, como presidente de la Sociedad de Alumnos, en "Un 'cuartelazo' a Diego Rivera", en El Nacional Revolucionario, 9 de mayo de 1930, p. I. Sobre sus estudios de derecho me informaron personalmente su viuda, Giovanna Serredi, y su hijo, Manuel del Castillo Negrete Serredi. 
Figura 9. Rivera se enfrenta a la élite estudiantil. Salvador Pruneda,

"Diego Rivera y sus discípulos", en El Nacional Revolucionario, México, 3 de abril de 1930, p. 3. Foto: HE.

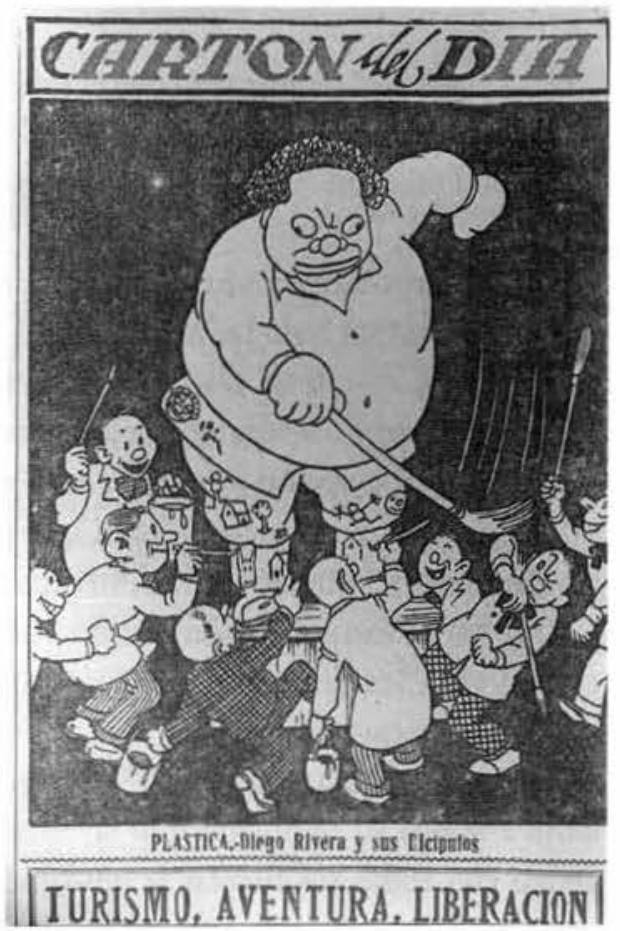

estaba en juego también otro problema: en el fondo, lo que se discutía era quién tenía derecho a juzgar a quién. Antes de la sesión del I4 de mayo, Rivera negó enfáticamente que fuera a "comparecer" a juicio; "si tal fuera, no comparecería". ${ }^{95} \mathrm{Al}$ leerse la propuesta de la comisión, Antonio Caso explicó prolijamente por qué se oponía a que se "inspeccionara" a los directores:

Correspondo en efecto a otra época y me glorio en ello, en que cada hombre tenía la absoluta individualidad y responsabilidad de sus actos y no toleraba por ningún medio ni motivo que nadie se los inspeccionase, $y$ estaba dispuesto a renunciar al cargo que ocupaba si en ese se veía una levísima falta de cumplimiento. ${ }^{6}$

95. "El Consejo Universitario va a resolver el conflicto estudiantil hoy mismo", en $\mathrm{El} \mathrm{Na}$ cional Revolucionario, 14 de mayo de 1930 , pp. I y 4 . No obstante, el propio Rivera, en un anteproyecto de reglamento de las Academias Mixtas, consideró la posibilidad de que éstas pidieran su renuncia a los directores; véase Diego Rivera, "Remitiendo un reglamento ante-proyecto Academias", CESU, REC, caja 31, exp. 398 (antes caja 1, exp. 2), 9 de abril de 1930, p. 33.

96. “Acta y transcripción taquigráfica...", p. 249. 
[...] y además, porque creo que el más grave mal de que adolece el país es la falta de respeto a la autoridad [...] Cuando se pusiera en tela de juicio mi conducta como Director $[. .$.$] mi individualismo tecalcitrante me ordenaría irme a casa. { }^{97}$

Los consejeros habían abandonado la idea de usar levita, pero es posible que la trajeran puesta bajo la "americana".

Cuando, en plena disputa, Rivera llamó en su auxilio a la policía, los alumnos de arquitectura se quejaron con el rector García Téllez de su "indisciplina", y él convino con ellos en "desaprobar" la actuación del director, exhortándolos a la cordura "para que por nosotros mismos, sin intervención de elementos extraños a la Universidad se resuelva este conflicto".$^{98}$ Les aclaró, sin embargo, que no estaba entre sus facultades imponer medidas disciplinarias a los directores. La comisión del cu propuso suspender temporalmente en su cargo a Rivera y que se procediera a averiguar si tenía de su parte a la mayoría de la comunidad. ${ }^{99}$ Aunque al principio Vicente Lombardo Toledano expresó su temor de que tal medida implicara una condena anticipada, apoyó con todas sus fuerzas la posibilidad de "juzgar" a cualquier funcionario, pues "ya comprenderéis que no tenemos detecho de comparar a Diego Rivera con el Maestro Caso" " ${ }^{\text {ro }}$ Chico Goerne abundó: "No señores, del Rector abajo todo es tocable, y sólo siendo todos tocables, podrá ser esto una cosa sana." Convino, sin embargo, en que Caso era una excepción a esa regla. ${ }^{\text {Ior }}$

Cabe hacer notar que si el dictamen de la comisión implicaba la separación de Rivera en caso de no contar con la mayoría, en caso contrario la Sociedad de Alumnos decidiría "bajo su estricta responsabilidad" si era de convocarse a una nueva elección. ${ }^{102}$ Gómez Arias opinaba que "Bien o mal,

97. "Renunció a la dirección de la Escuela...", p. 7

98. Ignacio García Téllez, "Declaraciones del rector a los alumnos de arquitectura que se presentaron ante él el día 9 del corri", CeSU, REC, caja 3I, exp. 398 (antes caja I, exp. 2), 9 de mayo de 1930, pp. 37-40.

99. Chico Goeme et al., "Dictamen que somete .", pp $7 \mathrm{I}-75$.

I00. "Acta y transcripción taquigráfica...", pp 206, 244-245 y $26 \mathrm{r}$.

ror. Ibidem, p. 250 El líder estudiantil, luego "escritor revolucionario", Baltazar Dromundo, declaró que la teforma universitaria implicaba tanto la patticipación de la juventud en el gobienno como la transparencia de los funcionarios, que no debían ser intocables. Véase "No existe división en la Universidad", en El Nacional Revolucionario, 22 de mayo de 1930, pp. I y 8

102. Chico Goeme, et al., "Dictamen que somete....", pp. 7I-75. 
Figura 1o. El rector Garcia Téllez es martirizado por los lideres inconformes. Salvador Pruneda, "Ecce hommo", en El Nacional Revolucionario, México, 3 de septiembre de 1930, p. 3 . Foto: IIE.

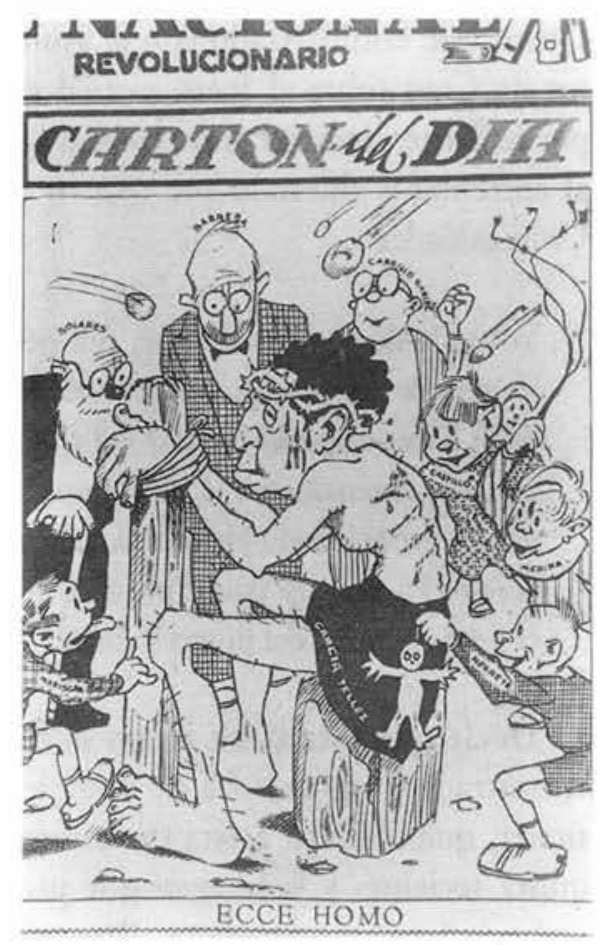

la Federación de Estudiantes es la única que puede decidir sobre la validez de la Sociedad de Alumnos de la Escuela de Artes Plásticas y de los actos que de ella dimanen". ${ }^{103}$ Finalmente, los estudiantes inconformes se salieron con la suya y aunque la comisión investigadora canceló la inscripción de 84 estudiantes, ello no provocó una nueva convocatoria para conformar la Sociedad de Alumnos. ${ }^{104}$ Esto es: que se podía juzgar a los directores, pero no a la Federación de Estudiantes.

El problema anterior no es superficial. Por una parte, en las constantes intervenciones de Lombardo Toledano y de Caso comenzó a dibujarse el importante debate sobre la orientación doctrinaria de la Universidad. ${ }^{105}$

I03. “Acta y transcripción taquigráfica...”, p. 195.

104. Vicente Lombardo Toledano, “Al C. Ignacio García Téllez...”, cesu, ReC, caja 31, exp. 398 (antes caja 1, $\exp 2$ ), I4 de junio de 1930, p. 79.

105. Un buen resumen del mismo es el que proporciona Alma Dorantes, El conflicto universitario en Guadalajara, 1933-1937, Guadalajara, Gobierno del Estado de Jalisco-Secretaría de Cultura-Consejo Nacional para la Cultura y las Artes-Instituto Nacional de Antropología e Historia, 1993. Dorantes considera que el conflicto sobre la "educación socialista" y el papel 
Quien esté familiatizado con el asunto lo habrá reconocido en los argumentos de Caso sobre el fuero virtual que atribuía a los directores; Lombardo, por su parte, dejó ver con claridad la que sería su posición tres años después, al enfrentarse abiertamente con su maestro durante el Primer Congreso de Universidades:

Yo estoy de acuerdo en que, por otra parte, el que va a trabajar a un establecimiento de orientación, que es todo establecimiento de cultura, de enseñanza, no debe hacer el papel natural del que deja que se mantenga la pugna ideológica, para que buenamente el alumno tome de su profesor lo que más le convenga; yo me he pronunciado en contra de esa falta de valer en materia de orientación de cultura en nuestro país. Porque el neutral, en todas las actividades de la vida, es el peor enemigo del progreso de un país."

Decir que estaba en juego la facultad de juzgar es tanto como haber encontrado lo que estaba en discusión implícitamente: la autonomía universitaria, que liberaba a ésta de la tutela del gobierno. Se trataba de una conquista reciente, y la imagen que proyectara la Universidad hacia el exterior preocupaba a sus consejeros. Rivera no había perdido oportunidad de señalar que José de León Toral, asesino del presidente Obregón, había sido alumno de Germán Gedovius. ${ }^{107}$ Cuidadoso, el secretario de la Unam propuso que Rivera fuese sustituido por Vicente Lombardo Toledano, que nada tenía que ver con el mundo de las artes, pues "con la salida del señor Rivera va a pensarse que la Universidad va a dar un paso hacia atrás, en ningún sentido debe admitirse ésto; todos estamos interesados y dispuestos a sostener el plan de

de las universidades se gestó desde el maximato, particularmente en el ámbito tegional. Señala que durante el Primer Congreso de Universidades, en 1933, que vio la polémica Caso-Lombardo, las posiciones más proclives a la "educación socialista" fueron propuestas por la delegación jalisciense.

106. "Acta y transcripción taquigráfica... ., p. 243 .

107. El argumento proviene de los treintatreintistas. Véase González Matute, ;30-30! contra la Academia de Pintura, hoja suelta; "La batalla de pintores y arquitectos", en El Universal, 29 de abril de 1930, p. I, y "Acta y transcripción taquigtáfica..", p. 169 Por cietto que Toral sí fue alumno de Gedovius, y no de los mejores. En una lista de calificaciones de 1926 aparece con promedio de $\mathrm{B}$, en tanto que Alfredo Zalce había conseguido mucho mejores notas con el mismo viejo profesor: Germán Gedovius, "Lista de los alumnos de la clase de pintura de figura", CESU, ESC-NAI (FESA), caja 8, exp. I, s.n., 22 de noviembre de 1926. 
estudio que aprobó la Gran Comisión del Consejo Universitario. La categoría ideológica del señor Lombardo Toledano nos dejaría a salvo de cualquier

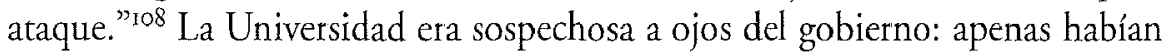
pasado seis meses desde el fin del último proceso electoral, donde numerosos universitarios habían apoyado notoriamente la candidatura opositora de Vasconcelos ${ }^{\text {I09 }}$

Pero la angustia del secretario de la unam y de los consejeros era un poco exagerada. En el periódico oficial y oficioso, El Nacional, la tendencia más importante fue quitarle importancia al asunto "Gustavo Ortiz Hernán, por ejemplo, se quejó de que "se mezcle a la Revolución en chismes de índole interescolar. Nada tiene que ver el marxismo que profesa Diego, con la enemistad tradicional entre arquitectos y pintores. Y menos aún la Revolución mexicana. La pugna es de carácter meramente administrativo. Podría resolverla el conserje del edificio..." "ıо Ya fuera por decisión personal o por línea editorial, los cronistas de ese periódico normalmente intolerante se preocuparon por demostrar que la universidad no era antirrevolucionaria. ${ }^{\mathrm{III}}$ Dentro de la UNAm había opiniones que avalaban ese cuidado, como la de Lombatdo: "Y no creo que haya una sóla opinión en contra, de que las nuevas orientaciones son las teorías del Gobierno Universitario, no sólo en materia estéti$\mathrm{ca}$, sino en todas las disciplinas que la universidad cultiva"; ;112 aunque tampoco faltaban observaciones sueltas que mostraban la resistencia no sistemática de un sector, como cuando Caso afirmó que "el más grave mal de que adolece el país es la falta de respeto a la autoridad", ${ }^{113}$ o cuando el consejero Cordero Amador se opuso a la admisión (defendida por Rivera) de obreros en el cu porque "para eso no se ha creado autónoma [la Universidad], o

I08. "Acta y transcripción taquigráfica...", p. 265.

Iog. Véase Skirius, op. cit, passim.

ro. Gustavo Ortiz Hernán, "Diego Rivera", en El Nacional Revolucionario, 4 de abril de I930, pp II-I. Sin embargo, su compañero de columna, Héctor Pérez Martínez, lamentaba que con frecuencia el ala conservadora del cu se impusiera sobre Gatcía Téllez, como en el caso de Rivera: Héctor Pérez Martínez, "Un balance de la Universidad", en El Nacional Revolucionario, 24 de mayo de 1930 , p. 3

III. Por ejemplo, "Han regresado los riveristas", en El Nacional Revolucionario, 23 de mayo de 1930 , pp. I y 8

II2. "Acta y transcripción taquigráfica...", p. 237

II3. Véase supra, nota IO4. 
nueva, sino al contrario, para ir contra la eterna Revolución en que ha vivido entre hermanos". II4

\section{La vanguardia y la opinión pública}

En suma, el intento de Rivera por denunciar el "reaccionarismo" que lo había sacado de la ECAP tuvo poco eco, ${ }^{\mathrm{II}}$ pero tampoco fue su argumento más poderoso. A Rivera se le atribuye la autoría de uno de los manifiestos relacionados con el movimiento treintatreintista. El consejero Favela y otros se quejaton de que se hubiera nombrado director a alguien que, antes de dirigir la Academia, había escrito "libelos" en su contra. ${ }^{\mathrm{II}}$ Pero eso, ser artista moderno, escribir manifiestos y oponerse a las vicjas ideas en arte, era la principal arma de Rivera. El consejero José Romano Muñoz apoyó su candidatura porque "creo que estamos en [....] un momento de apoyar a los iconoclastas" "I17 Unánimemente, la prensa lamentó que con el incidente quedara excluida la modernidad de la Academia, restó importancia al radicalismo político del director y pareció sumarse a la opinión socarrona de Gustavo Ortiz Hernán: "Diego Rivera tiene asegurada por su obra pictórica la gloria tomántica que tanto amaban los participantes en los festines literarios de Murger." II8 Sus ideas sobre la pintura eran vistas como "la señal inequívoca de [...] un vigotoso resurgimiento nacional". In "La revolución que en el dominio del arte esperan todos en México, es la nacionalización del arte; no precisamente la proletarización del mismo." "I20 Héctor Pérez Martínez la-

II4. "I a Universidad se ha desenmascarado; a nadie puede caber la duda de su posición de clase contra los trabajadores; por su propia confesión se ha denunciado ella misma [...] sabía que mi expulsión de su seno sería interpretada [....] como una expresión de reaccionarismo y [.... así se dijo en su Consejo", "Acta y transcripción taquigráfica ...", pp. 2IO-2II.

Irs. Tibol, Diego Rivera, , p. 99

II6. González Matute, 330-30' contra la Academia de Pintura, p. 5I, y "Acta y transcripción taquigráfica "..", p. 235

II7. "Papeles de la sesión...", p. 7.

II8. Gustavo Ortiz Hernán, "Desafios", en El Nacional Revolucionario, 27 de abril de 1930, p. II-I, il.

II9. "El inquietante e inquieto Diego Rivera" (editorial), en El Nacional Revolucionario, 4 de abril de r930, p 3

120. "El pasado conflicto en Bellas Artes", en El Nacional Revolucionario, 3I de mayo de I930, p. 3. 
mentó que los jóvenes profesores de la ECAP buscaran, absurdamente, alejarse de Rivera. ${ }^{121}$ El Universal, más discreto en esta época no muy propicia a la libertad de prensa, pero también con más olfato, entendió los antecedentes que daban legitimidad a su vanguardismo:

Don Diego Rivera, pintor revolucionario, es uno de los pocos fermentos de escándalo ideológico que nos quedan, desaparecido el señor Bulnes y callado voluntariamente don Luis Cabrera. Cada vez que habla el señor Rivera, produce un tumultuoso desencadenamiento de opiniones. Podría creerse que precisamente despliega sus carnosos labios con este solo objeto. ${ }^{122}$

Rivera aprovechó a fondo este espacio favorable en la "opinión pública" y por lo menos en ese terreno retórico su victoria fue total. Nunca dejó de recordar al rector que ambos se debían solidaridad como "revolucionarios"; ${ }^{23}$ pero su argumento más importante, ante él y ante el cu, era que sus decisiones no afectarían solamente

A MI PERSONA SINO AL ARIE MEXICANO, AL ARIE UNIVERSAL [.... $]^{124}$

La Universidad de México está o no está de acuerdo con el valor ideológico y estético de la producción artística actual de México [.... no hablo por mí sino de las gentes que están tras de mí, el arte mexicano moderno triunfará con, dentro, por, sin, sobre, contra la Universidad. No depende el triunfo estético ni el porvenir ideológico, ni el porvenir vital de un país, de ninguna institución. ${ }^{\mathrm{I} S}$

Gómez Arias, que meses antes había manifestado su impaciencia por escribir loores a su ahora rival, hizo un tímido intento por lamentar que "en la

I2 I. Héctor Pérez Martínez, "Escaparate", en El Nacional Revolucionario, is de julio de I930, p. 3. De manera parecida opinó Roberto Quirós Martínez, "El conflicto de Bellas Artes", en El Nacional Revolucionario, I2 de abril de 1930, pp. 3 y 5

I22. "Por el ojo de la llave; arquitectura y olores", en El Universal, 3 de abril de I930, p. 3.

123. Por ejemplo, en Diego Rivera, "Dando gracias por las declaraciones a la prensa", CEsu, REC, caja 3r, exp. 398 (antes caja I, exp 2), 2 de abril de I930, f. I3, le da gracias por sus expresiones de apoyo "que eran de esperarse dada la posición social y revolucionaria en que se encuentra usted colocado"

I24. Diego Rivera, "Al C. Rector de la Universidad Nac Autónoma...", CEsU, REC, caja 3I, exp. 398 (antes caja I, exp. 2), 28 de abril de 1930, pp. 17-28. Las mayúsculas están en el original.

I25. "Acta y transcripción taquigráfica....", pp. 179 y 257. 


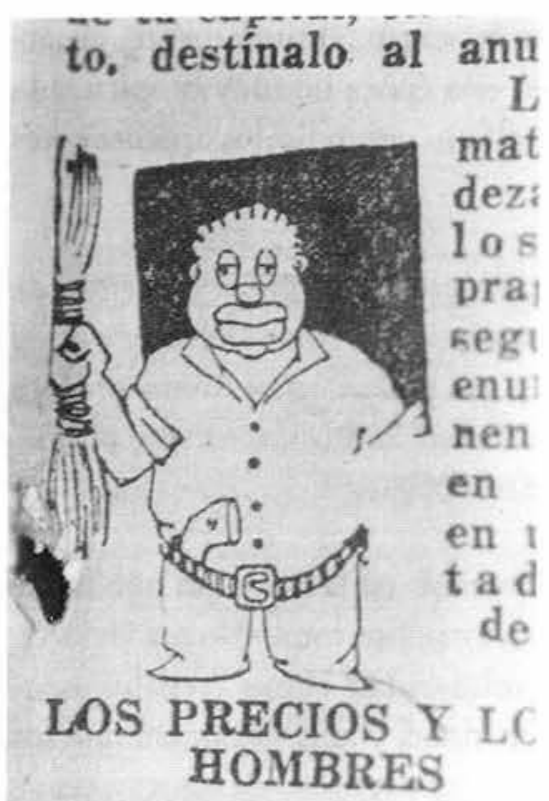

\section{Quienes atacan vio} grosero materialismo
Figura II. Rivera era apreciado como pintor, no necesariamente como revolucionario. Salvador Pruneda, vin̄eta, en Gustavo Ortiz Hernán, "Diego Rivera", en El Nacional Revolucionario, México, 4 de abril de 1930, p. II-I. Foto: IIE.

pintura mexicana no haya habido un sólo genio", ${ }^{126}$ pero el sentimiento general lo expresó, con impotencia, el consejero Favela:

Nosotros hemos faltado a la honorabilidad, que hemos faltado al señor Diego Rivera, que hemos faltado a la Rectoría, que hemos faltado a la cultura de México $\mathrm{y}$ a nuestros deberes de estudiantes $\mathrm{y}$ a la Universidad $[\ldots]^{127}$

Una fotografía tomada dos semanas después de la sesión del I4 de mayo muestra el festejo en el Anfiteatro Bolívar por el primer aniversario de la autonomía universitaria. Los estudiantes y funcionarios de la UNAM aparecen con el mural de Diego Rivera a sus espaldas. ${ }^{128}$ Lo que demuestra esta imagen es la posición ambivalente de las élites mexicanas frente al discurso vanguardista. Éste podía ser fuente de legitimidad: la UNAM era promotora

126. Ibidem, p. 195.

127. Ibidem, p. 231.

128. "El doctor Pedro de Alba, director de la Escuela Nacional Preparatoria...", en El Nacional Revolucionario, 27 de mayo de 1930, pp. II-1. 


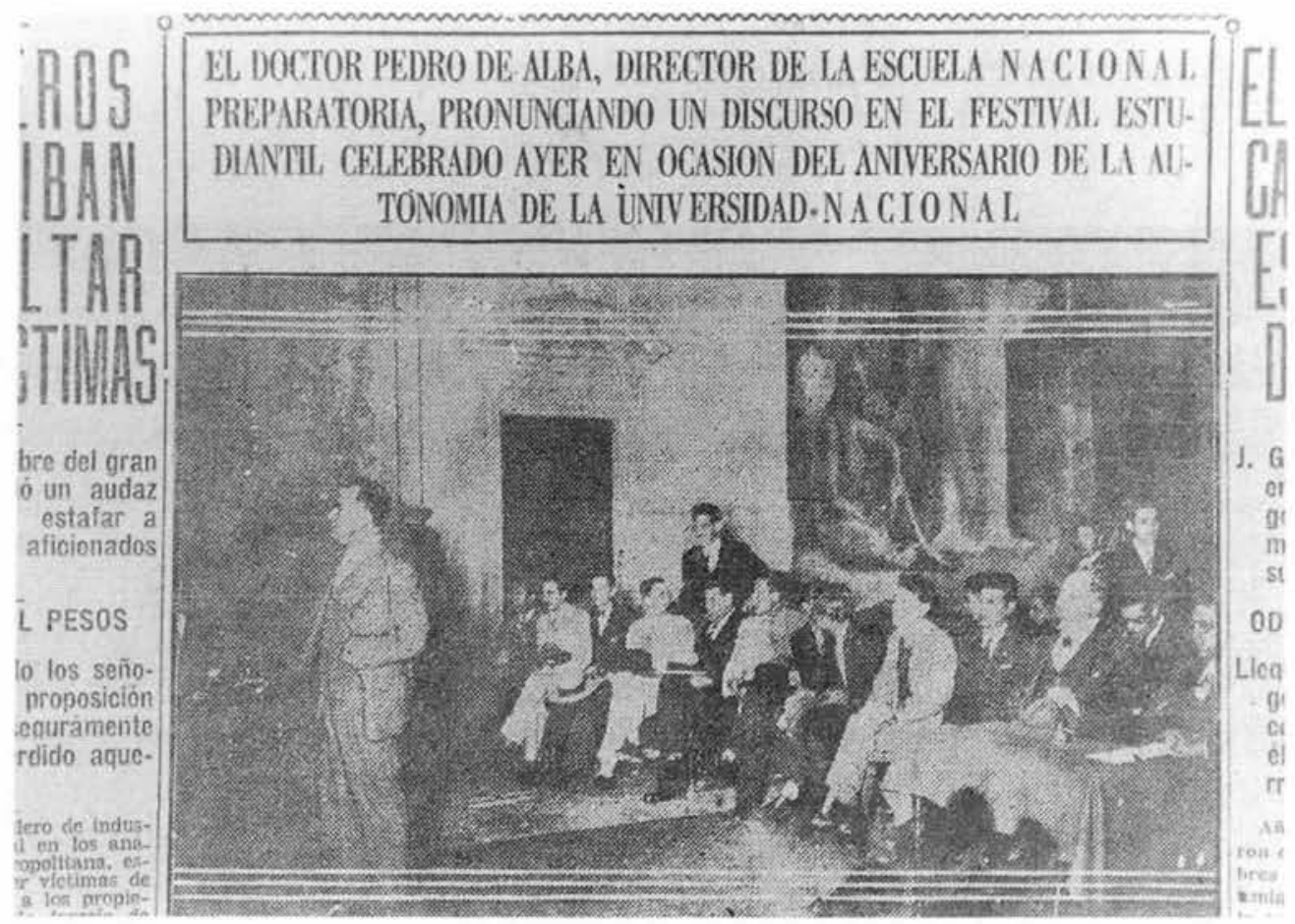

Figura 12. Inauguración de cursos en la unam, 1930. "El doctor Pedro de Alba, director de la Escuela Nacional Preparatoria...”, en El Nacional Revolucionario, México, 27 de mayo de 1930, p. II-2. Foto: IIE.

cultural, recibía las manifestaciones más avanzadas del modernismo pictórico, la pared de su auditorio principal tenía conspicuas alegorías de las artes y el conocimiento. Sin embargo, esas mismas élites no estaban en la disposición de llevar a la práctica lo que pudiera haber de vanguardista en el discurso de Rivera, que era opuesto a la idea de "difusión cultural" que se tenía desde los tiempos del Ateneo. Rivera era tolerable, incluso bien recibido, mientras sus murales sólo se sumaran a la gran masa de discursos a los que todo el mundo era afecto, en especial los estudiantes universitarios. ${ }^{129}$

Pero si se sospechaba que podía pasar a los hechos, dar por terminada la comedia de Murger, Casona o Jardiel Poncela y escenificar en su lugar una escena brechtiana con trabajadores de overol y extravagantes escenografías

129. La popularidad de la oratoria puede medirse, por ejemplo, por el concurso que convocó El Universal en abril de 1930: "El valor cultural del concurso de oratoria", en El Universal, 14 de abril de 1930, p. 3. 


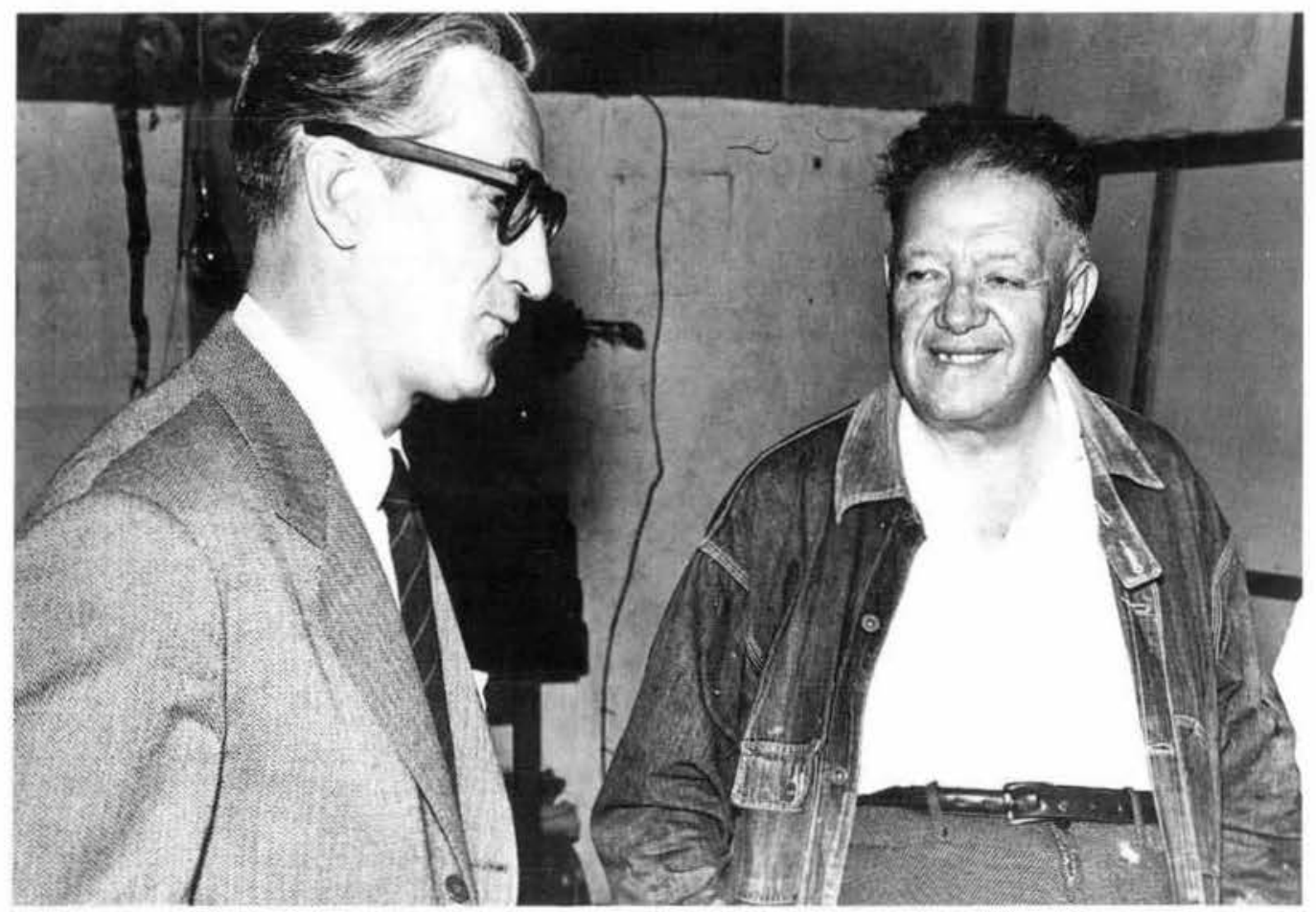

Figura 13. Manuel del Castillo Negrete y Diego Rivera, c. 1955. Foto: Enrique Segarra, acervo Giovanna Serredi. 
modernistas, en ese caso Rivera no sería bien recibido en la Universidad, y fuera de ella apenas se le daría más crédito a sus fantasías que al "dramón de capa y espada" ${ }^{\text {30 }}$ que se desarrollaba intramuros. En general, el discurso vanguardista no fue aceptado en México más que como retórica: pasar a los hechos era pasar al desempleo o a la cárcel. De ahí que, entre muchas tendencias posibles (en esta época Rivera tenía varios caminos frente a sí), el muralismo prevaleciera una y otra vez en la actividad de los pintores.

\section{Salida: Del Castillo Negrete}

La historia de Manuel del Castillo Negrete, a la que nos hemos teferido poco en estas líneas, abriría otras posibilidades de interpretación. ${ }^{331}$ Cuando el cuartelazo de los arquitectos lo dejó como presidente de la Sociedad de Alumnos y cabeza visible de los antirriveristas, ${ }^{\mathrm{1} 32}$ vivía como bohemo en una buhardilla sobre el Cabaret de la Rata Muerta. Un cuadro de sus tiempos de estudiante muestra las enseñanzas, directas o por interpósita persona, de Germán Gedovius: el color pastoso para reproducir con naturalismo las imperfecciones del modelo. En busca de elementos que le permitieran convertirse en pintor, frecuentó las facultades de química y medicina. Del Castillo Negrete se decepcionó de la pintura e hizo una pequeña fortuna en el negocio de bienes raíces, que dilapidó viajando por Europa.

Regresó al principio de los años sesenta, sin dinero, y por darse ocupación fundó la Escuela de Restauración, Coservación y Museografía que hoy lleva su nombre. Parece de una lógica absoluta, cruel, que andando el tiempo el opositor de Rivera haya iniciado en México la consetvación del "patrimonio" artístico. En una fotografía se le ve a fines de los años cincuenta con Diego Rivera. ${ }^{\mathrm{I} 33}$ Los dos parecen muy divertidos, pero era Castillo Negrete quien podía tener mayor motivo de regocijo, pues a largo plazo había ganado la batalla. El discurso de los valores culturales se había impuesto sobre la vanguardia: Rivera ya era un monumento viviente que necesitaba conservación. \$

130. La expresión es de Rivera; véase Moyssén, op. citt., p. 53.

I31. Todo lo que sigue me fue comunicado personalmente por Giovanna Sertedi viuda de Del Castillo Negrete.

132.. Véase supra, nota Ioo

133. La fotografía también me la proporcionó Giovanna Serredi viuda de Del Castillo Negrete. 
Fuentes

Archivo del Consejo Universitario, Universidad Nacional Autónoma de México, México.

CESU Archivo del Centro de Estudios sobre la Universidad, Universidad Nacional Autónoma de México, México

El Nacional. Diario Popular, México.

El Nacional Revolucionario, México.

El Universal, México

El Universal Gráfico, México.

La Vanguardia, Orizaba

Acevedo, Jesús T., Disertaciones de un arquitecto. Prólogo de Justino Fernández, notas de Alfonso Mariscal, México, Instituto Nacional de Bellas Artes, 1967 (Ayer y Hoy, 5).

Alfaro Siqueiros, David, Me llamaban "El Coronelazo". México, Grijalbo, I977 (Biografías Gandesa).

Altamirano Piolle, María Elena, "José María Velasco: paisajes de luz, horizontes de modernidad", en Homenaje nacional a José Maria Velasco. Catálogo de exposición en el Museo Nacional de Arte, julio-octubre de 1993, México, Instituto Nacional de Bellas ArtesMuseo Nacional de Aste, 1993, pp. 35-503.

Azuela, Alicia, "Rivera and the Concept of Proletarian Art", en Diego Rivera: A Retrospective. Catálogo de exposición en el Instituto de Artes de Detroit, Nueva York, W.W. Norton, I986, pp. I25-129.

Báez Macías, Eduardo, "La Academia de San Carlos en la Nueva España como instrumento de cambio", en Las academias de arte. VII Coloquio Internacional de Historia del Arte. México, Universidad Nacional Autónoma de México-Instituto de Investigaciones Estéticas, 1985 , pp. 33-58.

Cardoza y Aragón, Luis, Orozco México, Universidad Nacional Autónoma de México-Instituto de Investigaciones Estéticas, I959.

Cordero Reiman, Karen, “Alfredo Ramos Martínez: 'un pintor de mujeres y de flores' ante el ámbito estético posrevolucionario", en Alfredo Ramos Martinez (I87I-1946), una visión retrospectiva Catálogo de exposición en el Museo Nacional de Arte, abtil-junio de 1992, México, Instituto Nacional de Bellas Artes-Museo Nacional de Arte, 1992, pp. $6 \mathrm{I}-78$.

Charlot, Jean, El renacimiento del muralismo mexicano, Ig20-I925. México, Domés, I985

—- Mexican Art and the Academy of San Carlos, I785-1915. Austin, Texas University Press, I $962 \ldots$

Debroise, Olivier, "Hotel Bristol, Tverskaya 39", en Curare, México, núm. 5, 1995, pp. 4-8.

Dorantes, Alma, El conflicto universitario en Guadalajara, I933-1937. Guadalajara, Gobierno del Estado de Jalisco-Secretaría de Cultura-Consejo Nacional para la Cultura y las ArtesInstituto Nacional de Antropología e Historia, I993. 
García, Pilar, "Alfredo Ramos Martínez y la Academia Nacional de Bellas Artes", en Alfredo Ramos Martínez (I871-1946), una visión restrospectiva Catálogo de exposición en el $\mathrm{Mu}$ seo Nacional de Arte, abril-junio de 1992, México, Instituto Nacional de Bellas ArtesMuseo Nacional de Arte, 1992, pp. 33-57.

Garibay S., Roberto, Breve historia de la Academia de San Carlos y de la Escuela Nacional de Artes Plásticas. México, Universidad Nacional Autónoma de México-Escuela Nacional de Artes Plásticas, 1990

González Matute, Laura, "Documentos del gtupo de pintores i30-30!" (tecopilación documental incluida en la caja del catálogo), en ;30-30! contra la Academia de Pintura. Catálogo de exposición en el Museo Nacional de Arte, incluye estudio, documentos y folletería, México, Instituto Nacional de Bellas Artes-Museo Nacional de Aute, 1993.

_- Escuelas de pintura al aire libre y centros populares de pintura. México, Instituto Nacional de Bellas Artes-Centro de Información y Documentación en Artes Plásticas, 1987 (Investigación y Documentación, 2).

__ , 30-30! contra la Academia de Pintura. México, Instituto Nacional de Bellas ArtesMuseo Nacional de Arte, 1993

Hale, Charles $A_{n}$, La transformación del liberalismo en México a fines del siglo XIX. México, Vuelta, 199I (La Reflexión)

Krauze, Enrique, Caudillos culturales en la Revolución mexicana. México, Siglo VeintiunoSecretaría de Educación Pública, 1985.

Lodder, Cristina, El constructivismo ruso. Madrid, Alianza, 1988 (Alianza Forma).

López Rangel, Rafael, Diego Rivera y la arquitectura mexicand. Comentario crítico de Entique Yánez, México, Secretaría de Eduación Pública, 1986.

Martínez, José Luis, comp, Alfonso Reyes-Pedro Henríquez Ureña, correspondencia Igo7-I9I4. México, Fondo de Cultura Económica, 1986, vol. I.

Moreno, Salvador, El pintor Antonio Fabrés. México, Universidad Nacional Autónoma de México-Instituto de Investigaciones Estéticas, 1981

Moyssén, Xavier, comp., Diego Rivera, textos de arte México, Universidad Nacional Autónoma de México-Instituto de Investigaciones Estéticas, 1986.

Orozco, José Clemente, Autobiografia. México, Era-Sectetaría de Educación Pública, 1983.

Ramírez, Fausto, "La obra de Germán Gedovius: una reconsideración", en Germán Gedovius, una generación entre dos siglos. Catálogo de exposición en el Museo Nacional de Arte, México, Instituto Nacional de Bellas Artes, 1084, pp. 9-33

__- "Tradición y modernidad en la Escuela Nacional de Bellas Artes, 1903-1912", en Las academias de arte VII Coloquio Internacional de Historia del Arte. México, Universidad Nacional Autónoma de México-Instituto de Investigaciones Estéticas, I985, pp. 209-2.59.

Reyes Palma, Francisco, Historia social de la educación artística en México. México, Secretaría de Educación Pública-Instituto Nacional de Bellas Artes, I984.

Richardson, William, "The Dilemmas of a Communist Attist: Diego Rivera in Moscow, 1927-1928", en Mexican Studies/Estudios Mexicanos, Irvine (California), vol 3, núm. 2, invierno 1987 , pp. 49-69.

Skirius, John, José Vasconcelos y la cruzada de rg29. México, Siglo Veintiuno, 1978 (Historia). 
Strigalev, Anatolii, "Nonarchitects in Architecture", en The Great Utopid. The Russian and Soviet Avant-Garde, 19I5-1932. Catálogo de exposición en el Museo Guggenheim, Nueva York, septiembre-diciembre de 1992, curadora Jane Sharp, Nueva York, Guggenheim Museum, 1992, pp. 665-679.

Tenorio, Mauricio, "A Tropical Cuauhtémoc: Celebtrating the Cosmic Race a the Guanabara Bay”, en Anales del Instituto de Investigaciones Estéticas, vol. xv1, núm 65, 1994, pp. 93-137. Tibol, Raquel, comp., Diego Rivera; arte y politica. México, Grijalbo, I979 (Teoría y Praxis).

Tibol, Raquel, "Ias escuelas al aire libre en el desarıollo cultural de México", en Sylvia Pandolfi, comp., Homenaje al movimiento de escuelas de pintura al aire libre. México, Instituto Nacional de Bellas Artes, 1981, pp. 16-49.

Torriente, Loló de la, Mernoria y razón de Diego Rivera México, Renacimiento, 1959, 2. vols. Wood, Paul, "The Politics of the Avant-Garde", en The Great Utopia; The Russian and Soviet Avant-Garde, rgoo-rgIs. Catálogo de exposición en el Museo Guggenheim, septiembre-diciembie de I992, curadora Jane Sharp, Nueva York, Guggenheim Museum, I992, pp. I-24 